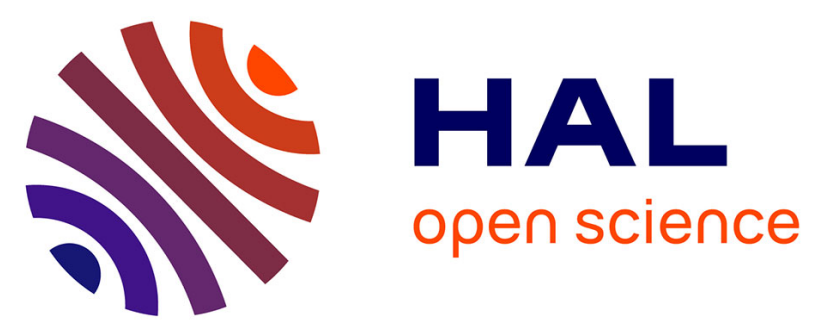

\title{
Insights into Redox Reactions and Ionic Transfers in Nickel/Iron Layered Double Hydroxide in Potassium Hydroxide
}

Elise Duquesne, Stéphanie Betelu, Cyrille Bazin, Alain Seron, Ioannis Ignatiadis, Hubert Perrot, Ozlem Sel, Catherine Debiemme-Chouvy

\section{To cite this version:}

Elise Duquesne, Stéphanie Betelu, Cyrille Bazin, Alain Seron, Ioannis Ignatiadis, et al.. Insights into Redox Reactions and Ionic Transfers in Nickel/Iron Layered Double Hydroxide in Potassium Hydroxide. Journal of Physical Chemistry C, 2020, 124 (5), pp.3037-3049. 10.1021/acs.jpcc.9b09699 . hal-02470756

\section{HAL Id: hal-02470756 https://hal.sorbonne-universite.fr/hal-02470756}

Submitted on 7 Feb 2020

HAL is a multi-disciplinary open access archive for the deposit and dissemination of scientific research documents, whether they are published or not. The documents may come from teaching and research institutions in France or abroad, or from public or private research centers.
L'archive ouverte pluridisciplinaire HAL, est destinée au dépôt et à la diffusion de documents scientifiques de niveau recherche, publiés ou non, émanant des établissements d'enseignement et de recherche français ou étrangers, des laboratoires publics ou privés. 


\section{Insights into redox reactions and ionic transfers in $\mathrm{Ni} / \mathrm{Fe}$ layered}

\section{double hydroxide in potassium hydroxide}

Elise Duquesne, ${ }^{\mathrm{a}, \mathrm{b}}$ Stéphanie Betelu, ${ }^{\mathrm{b}}$ Cyrille Bazin, ${ }^{\mathrm{a}}$ Alain Seron, ${ }^{\mathrm{b}}$ Ioannis Ignatiadis, ${ }^{\mathrm{b}}$ Hubert Perrot, ${ }^{\mathrm{a}}$ Ozlem Sel, ${ }^{\mathrm{a}}$ Catherine Debiemme-Chouvy, ${ }^{\mathrm{a}^{*}}$

a Sorbonne Université, CNRS, Laboratoire Interfaces et Systèmes Électrochimiques, LISE, UMR 8235, 4 place Jussieu, 75005 Paris, France

${ }^{b}$ Bureau de Recherches Géologiques et Minières, 3 Avenue Claude Guillemin, 45100 Orléans, France 
ABSTRACT: The pseudo-capacitive properties and the mixed cation/anion-exchanger nature of layered double hydroxides (LDHs) were highlighted via in situ electrochemical and physicochemical analyses conducted in a $\mathrm{KOH}$ solution $(1 \mathrm{~mol} / \mathrm{L})$ on a nano-Ni/Fe-LDH film. The reversible Ni(II)/Ni(III) oxidation/reduction reaction was monitored using an electrochemical quartz crystal microbalance (EQCM). The coupling of powerful electrochemical methods, EQCM and ac-electrogravimetry, and physicochemical techniques, EDX, XPS and in situ XRD, provided results clarifying the corresponding mass transfer mechanisms. $A c$-electrogravimetry identified the nature, in terms of molar mass, kinetics and concentration variation of all reversibly transferred species associated with the redox reactions involving Ni and water molecules. This methodology demonstrated a reversible anion intercalation/de-intercalation into/from the interlayer spacing, in agreement with the redox reactions leading to modulate the electric charge of the layers. This phenomenon was also identified by in situ XRD. In addition, the variation of the $\mathrm{pH}$ at the $\mathrm{LDH} /$ electrolyte interface via a catalysed oxygen evolution reaction (OER) leads to cation electro-adsorption/desorption onto/from the external LDH surfaces. 


\section{INTRODUCTION}

A layered double hydroxide (LDH) material consists of stacked brucite layers, positively charged due to the substitution of some divalent $\mathrm{M}^{\mathrm{II}}$ cations by trivalent $\mathrm{M}^{\mathrm{III}}$ cations. This excess of positive charges is compensated by the presence of exchangeable hydrated anions in the interlayer space ${ }^{1}$, leading to the general formula $\left[\mathrm{M}(\mathrm{II})_{1-\mathrm{x}} \mathrm{M}(\mathrm{III})_{\mathrm{x}}(\mathrm{OH})_{2}\right]^{\mathrm{x}+}\left(\mathrm{A}^{\mathrm{n}-\mathrm{x} / \mathrm{n}}\right) \cdot \mathrm{mH}_{2} \mathrm{O}$.

Thus, LDHs have a high capacity for anion exchange (2-3 meq/g) comparable to that of anion exchange resins ${ }^{2,3}$. This renders them attractive for controlled anion release (drug delivery ${ }^{4,5}$, soil fertilizer 6 ), anion containment (catalysis, anti-corrosion coating ${ }^{7,8}$ ) and anion entrapment (water treatment ${ }^{9}$ ). Competition between anion species was first shown by Miyata ${ }^{10}$ and fully described in other articles. ${ }^{11,12,13}$

Regarding applications in the field of energy storage or water treatment, the reversibility of ion transfer between an electrolyte and the basal space needs further investigation. Reversible ion transfer is controlled by tuning the oxidation state of metallic sites to generate a reversible modification of the positive charge excess within the layers. This phenomenon depends on the electrochemical accessibility of redox-active transition cations (ex: $\mathrm{Co}^{3+} / \mathrm{Co}^{2+}, \mathrm{Ni}^{3+} / \mathrm{Ni}^{2+}, \mathrm{Fe}^{3+} / \mathrm{Fe}^{2+}$ etc.) that participate in an electron hopping mechanism. ${ }^{14}$ The low electronic-conductivity performance of $\mathrm{LDHs}^{15}$ is promoted by preparing thin LDH films coated on a working electrode surface (glassy carbon, platinum, gold, indium tin oxide...) by solvent casting, layer-by-layer assembly, or electrochemically assisted deposition. ${ }^{14,1,16,17}$

Several studies that explored reversible ion transfer phenomena related to the cyclic oxidation/reduction of electroactive cations within the layers. ${ }^{1,18,19,20,21,22}$ showed the reversible intercalation of anions. Some also showed the contribution of cations, ${ }^{1,18,20,22}$ and proposed assumptions concerning the nature of the species; one suggested the transfer of electrolytic cations, ${ }^{20}$ another advanced anion intercalation/sorption influenced by electrolytic cations. ${ }^{1}$ There is also evidence of the transfer of ion pairs, ${ }^{22}$ or the loss of water molecules from the LDH interlayer space accompanied by a loss of protons from the LDH lattice. ${ }^{18}$ 
The redox reactivity of LDHs remains challenging to define, probably due to a duality of adsorption surface sites similar, by analogy, to cationic clay minerals. ${ }^{23,24,25,26,27,28,29,30}$ Indeed, basal surfaces of cationic clay minerals have a permanent negative charge caused by isomorphic cationic substitution, whereas edge surfaces have a variable proton surface charge caused by functional hydroxyl groups. The redox reactions involving redox-active transition cations modulate the electric charge of the layers. For nontronite $2 / 1$, the negative charge increase due to $\mathrm{Fe}(\mathrm{III})$ to $\mathrm{Fe}(\mathrm{II})$ reduction is balanced by the adsorption of cations into clay interlayers as well as by a specific sorption of protons from the solution. Prevalence of one compensating mechanism over another is related to the growing lattice distortion induced by Fe(III) reduction. At low reduction levels, interlayered cation adsorption dominates and some of the incorporated protons react with structural hydroxyl groups, leading to dehydroxylation of the structure. ${ }^{31}$

In addition, the reactivity of edge surfaces is strongly influenced by the net proton surface charge, which depends on $\mathrm{pH}$ and ionic strength, according to Brønsted-Lowry acid-base theory, through the following reactions:

$$
\begin{aligned}
& \equiv \mathrm{M}-\mathrm{OH}+\mathrm{H}^{+} \leftrightarrows \equiv \mathrm{M}^{-} \mathrm{OH}_{2}{ }^{+} \\
& \equiv \mathrm{M}-\mathrm{OH}+\mathrm{OH}^{-} \leftrightarrows \equiv \mathrm{M}^{-} \mathrm{O}^{-}+\mathrm{H}_{2} \mathrm{O}
\end{aligned}
$$

where $\mathrm{M}$ is a metal cation constituting the layered sheets and thus the clay edge surfaces. It implies the sorption of both cations and anions onto edge surfaces depending on the $\mathrm{pH}$ at the clay interface. In agreement with reaction 2, for $\mathrm{pH}>>\mathrm{pH}_{\mathrm{PZNC}}$ (point of zero net charge $\mathrm{pH}$ ), the species $\equiv \mathrm{M}^{-\mathrm{O}^{-}}$predominates, leading to cation sorption onto edge surfaces.

By analogy to cationic clay minerals, the redox reactions involving structural-transition cations of the LDHs should modulate the positive electric charge of the layers, thus modulating the anionic transfer capacity and, to a lesser extent, the desorption of protons from structural $\mathrm{OH}$ groups to maintain electroneutrality. The reactivity of the edge surfaces and external basal sites should also be strongly influenced by the net proton surface charge. 
To attribute the phenomena postulated by analogy with cationic clay minerals, the modification of the structural LDH charge via oxidation/reduction of part of the redox-active cations forming the layers should show the presence of anionic exchange sites. In addition, the use of a solution with a much higher $\mathrm{pH}$ than the $\mathrm{pH}$ PZNC should allow identifying cation sorption which takes place on the LDH external basal sites and edge surfaces in agreement with the following reaction:

$\equiv \mathrm{M}-\mathrm{OH}+\mathrm{OH}^{-}+\mathrm{C}^{+} \leftrightarrows \equiv \mathrm{M}-\mathrm{O}---\mathrm{C}+\mathrm{H}_{2} \mathrm{O}$

where $\mathrm{C}^{+}$is a cation coming from the supporting electrolyte.

For this purpose, electrochemical techniques are well suited, as they allow redox transition of LDH electroactive cations as well as the modulation of interfacial $\mathrm{pH}$ via electro-catalytic properties of $\mathrm{Ni} / \mathrm{Fe}$ LDHs versus water oxidation. ${ }^{32,33,34,35,36,37,38,39,40,41}$

In addition, the $a c$-electrogravimetry method that combines measuring the electrochemical impedance (intensity/potential transfer function) and the mass/potential transfer function, will identify the reversibly exchanged species in terms of anions, cations or neutral species, as well as their molar mass, ease/difficulty of transfer, exchanged concentration and exchanged mass for each species at different potentials. This method was validated in studies of hydroxide ${ }^{42}$ and oxide ${ }^{43}$ materials and conductive polymers. ${ }^{44}$ Our work provides new insight into the mechanisms of the interfacial redox reactions by exploiting ac-electrogravimetric methodology.

We paid special attention to $\mathrm{Ni} / \mathrm{Fe}-\mathrm{LDH} 6 / 2$, known to be one of the most conductive LDHs whose electroactive Ni can be reversibly switched to the (+II) and (+III) oxidation states under polarization. ${ }^{14}$ The use of nano-Ni/Fe-LDH 6/2 tends to enhance the number of transfer (intercalation and adsorption) sites onto both edge and basal surfaces. As Ni/Fe-LDH has a pHPZNC of 8 , this work was conducted in a $\mathrm{KOH} 1 \mathrm{~mol} / \mathrm{L}$ solution whose $\mathrm{pH}$ value is higher than the $\mathrm{pH}_{\mathrm{PZNC}}$, in order to induce cationic sorption onto LDH border sites. The catalysed oxidation reaction of water $\mathrm{r}^{45,46,47,48}$ helped modulating the $\mathrm{pH}$ value at the $\mathrm{LDH} /$ electrolyte interface. 
For the first time, we identified the nature of each reversibly transferred species (anions, cations and water molecules) related to redox reactions as well as determining the species kinetics. Energy-dispersive X-ray spectroscopy (EDX) and X-ray photoelectron spectroscopy (XPS) analyses confirmed the electrosorption of cations, corroborating the pseudo-capacitive properties of a mixed cation/anion exchanger. The electro-catalytic properties of the interlayered water molecules were evidenced. In addition, in situ X-ray diffraction (XRD) analysis of LDH under polarization contributed to our understanding of LDH hydration during cyclic oxidation/reduction, investigating the transfer of water molecules from/to the interlayer space.

\section{MATERIALS AND METHODS}

(i) Synthesis of LDH by Co-Precipitation. LDH was synthesized with the varying-pH method ${ }^{49}$ using bi-distilled water, $\mathrm{Ni}\left(\mathrm{NO}_{3}\right)_{2} .6 \mathrm{H}_{2} \mathrm{O}, \mathrm{Fe}\left(\mathrm{NO}_{3}\right)_{3} .9 \mathrm{H} 2 \mathrm{O}, \mathrm{Na}_{2} \mathrm{CO}_{3}(99.8 \%$ purity, Aldrich) and $\mathrm{NaOH}$ (98\% purity, Aldrich) in air at $35^{\circ} \mathrm{C}$. An aqueous salt solution with a molar ratio $\mathrm{Ni}{ }^{\mathrm{II}} / \mathrm{Fe}^{\mathrm{III}}=3$ was titrated with an alkaline aqueous solution containing $2.6 \mathrm{~mol} / \mathrm{L} \mathrm{NaOH}$ and $1 \mathrm{~mol} / \mathrm{L} \mathrm{Na}_{2} \mathrm{CO}_{3}$. This solution was introduced drop-by-drop with a peristaltic pump until the salt solution reached $\mathrm{pH} 10$. The slurry was then stirred for $24 \mathrm{hrs}$ at $60^{\circ} \mathrm{C}$ for maturation, which allowed the growth and crystallization of particles. To separate solids and residual solution, the slurry was centrifuged at $4000 \mathrm{rpm}$ for five minutes. The supernatant was eliminated, and the final material underwent dialysis in de-ionized water equilibrated by atmospheric $\mathrm{CO}_{2}$ renewed every day for five days to eliminate excess salts and allow $\mathrm{NO}_{3}{ }^{-}$to $\mathrm{CO}_{3}{ }^{2-}$ anion exchange.

(ii) Physical and Chemical Definition of the Ni/Fe-LDH Powder. To allow a structural characterization of the material, part of the $\mathrm{LDH}$ powder was dried in a furnace at $70^{\circ} \mathrm{C}$ for $48 \mathrm{hr}$. This was studied by powder X-ray diffraction (PXRD) with a Panalytical Empyrean diffractometer, using $\mathrm{Cu} \mathrm{K} \alpha$ radiation $(\lambda=1.541 \AA)$ operating at $45 \mathrm{kV}$ and $40 \mathrm{~mA}$ at room temperature. The diffractometer is equipped 
with a detector operating in scanning line mode using 255 channels. The scans were recorded from $4^{\circ}$ to $84^{\circ}(2 \theta)$ with a step of $0.026^{\circ}$ and an acquisition time of 1200 seconds per step.

The morphology of the particles forming the powder and the cationic molar ratio were examined under an Ultra55 Zeiss field-emission-gun scanning electron microscope (FEG-SEM), operating at $10 \mathrm{kV}$. The anions intercalated in the interlayer space were identified by XPS analysis (Escalab 250xi, Thermo electron). The number of water molecules was determined by TGA analyses, done with a Mettler Toledo DSC1/ATG State instrument in the temperature range of $20-1000^{\circ} \mathrm{C}$, at a heating rate of $1{ }^{\circ} \mathrm{C} / \mathrm{min}$, under air atmosphere.

(iii) Preparation and Characterization of LDH Thin Films. Ethanol was added to the LDH slurry in order to avoid LDHs particles agglomeration during further drying process. A drop of the resulting suspension was deposited on the gold electrode of quartz resonators $\left(\mathrm{A}=0.2 \mathrm{~cm}^{2}, 9 \mathrm{MHz}, \mathrm{AWS}\right.$ company, Spain) and the deposit was dried in air atmosphere. The LDH coating mass was then determined by quartz crystal microbalance (QCM) and its thickness was estimated by SEM.

\section{(iv) In situ Coupled Electrochemical Analyses of the LDH}

- EQCM measurements. EQCM measurements were performed in an aqueous solution of $1 \mathrm{~mol} / \mathrm{L}$

$\mathrm{KOH}$ using a three-electrode cell connected to an Autolab potentiostat-galvanostat electrochemical workstation coupled with a lab-made QCM device. The counter electrode was a platinum grid, the reference electrode was a mercury/mercurous sulphate one, all the potentials were converted to the standard hydrogen electrode (SHE). The working electrode (WE) was a $9 \mathrm{MHz}$-gold patterned quartz substrate coated with a thin film of LDH. Cyclic electrogravimetric measurements were recorded at $10 \mathrm{mV} / \mathrm{s}$ over a potential window from $0.45 \mathrm{~V}$ to $0.71 \mathrm{~V}$. Frequency changes $(\Delta f)$ of the quartz crystal resonator were monitored simultaneously with the current $(\Delta l)$. The $\Delta f$ was converted into the mass change $(\Delta m)$ of the quartz crystal by applying the Sauerbrey equation: ${ }^{50}$ 
$\Delta f=-\frac{2 f_{o}^{2}}{A \sqrt{p_{q} \mu_{q}}} \Delta m$

where $\mathrm{A}$ is the active surface of the gravimetric sensor, $\mathrm{p}_{\mathrm{q}}$ is the quartz density, $\mu_{\mathrm{q}}$ is the quartz shear modulus, and $\mathrm{f}_{0}$ is the fundamental resonance frequency of the quartz..$^{51}$

We note:

$\Delta f=-C \Delta m$

with $\mathrm{C}$, the experimental sensitivity constant, $16.31 \times 10^{7} \mathrm{~Hz} \mathrm{~g}^{-1} \mathrm{~cm}^{2}$ for $9 \mathrm{MHz} .{ }^{51}$

- Ac-electrogravimetric measurements. The ac-electrogravimetric setup was composed of a fourchannel frequency response analyser (FRA, Solartron 1254) coupled to a lab-made potentiostat (SOTELEM-PGSTAT) and a lab-made QCM operating under dynamic regime. ${ }^{52,53}$ The WE was polarized at a chosen potential, to which a sinusoidal small-amplitude potential perturbation $(80 \mathrm{mV}$ rms $)$ was superimposed. The microbalance frequency change $(\Delta f)$ related to the mass response $(\Delta m)$ of the modified WE was measured simultaneously with the current response $(\Delta I)$ of the electrochemical system. The resulting signals were sent to the four-channel FRA at the given potential and frequency modulation to obtain two main experimental transfer functions (TFs): electrogravimetric TF, $\left.\frac{\Delta m}{\Delta E}\right|_{\text {exp }}(\omega)$, and classical electrochemical impedance, $\left.\frac{\Delta E}{\Delta I}\right|_{\text {exp }}(\omega)$. The latter permits the experimental charge/potential transfer function $\left.\frac{\Delta q}{\Delta E}\right|_{\exp }(\omega)$ to be obtained:

$\left.\frac{\Delta q}{\Delta E}\right|_{\exp }(\omega)=\left.\frac{1}{j \omega} \frac{\Delta I}{\Delta E}\right|_{\exp }(\omega)$

From the experimental electrogravimetric transfer function, $\left.\frac{\Delta m}{\Delta E}\right|_{\text {exp }}(\omega)$, experimental partial transfer functions can be calculated, eliminating the contribution of an anion or a cation, if three species are taken 
into account: a cation (c), an anion (a) and solvent (s) (see SI file, part (iv) of ac-electrogravimetry theoretical part and data analysis). For example, if the contribution of the cation is extracted, the remaining experimental response of the anion and the solvent is calculated according to the following equation:

$\left.\frac{\Delta m}{\Delta E}\right|_{\exp } ^{a s}(\omega)=\left.\frac{\Delta m}{\Delta E}\right|_{\exp }(\omega)+\left.\frac{m_{c}}{F} \frac{\Delta q}{\Delta E}\right|_{\exp }(\omega)$

In a similar manner, if the contribution of the anion is extracted, it becomes:

$\left.\frac{\Delta m}{\Delta E}\right|_{\exp } ^{c s}(\omega)=\left.\frac{\Delta m}{\Delta E}\right|_{\exp }(\omega)-\left.\frac{m_{a}}{F} \frac{\Delta q}{\Delta E}\right|_{\exp }(\omega)$

The experimental TFs given above were fitted with the theoretical expressions (see Supporting Information) defined in a model based on the interfacial flux of species under polarization using Mathcad Software version 15 (PTC). Fitting procedure provided parameters $\left(K_{i}, G_{i}, R t_{i}=\frac{1}{F G_{i}}, M_{i}\right.$ and $\Delta C_{i}$ where $i$ is an anion, cation or free solvent) regarding the nature of the species transferred, together with their interfacial dynamics and their concentration variation in the electrode (see Supporting Information).

\section{In situ XRD measurements under polarization}

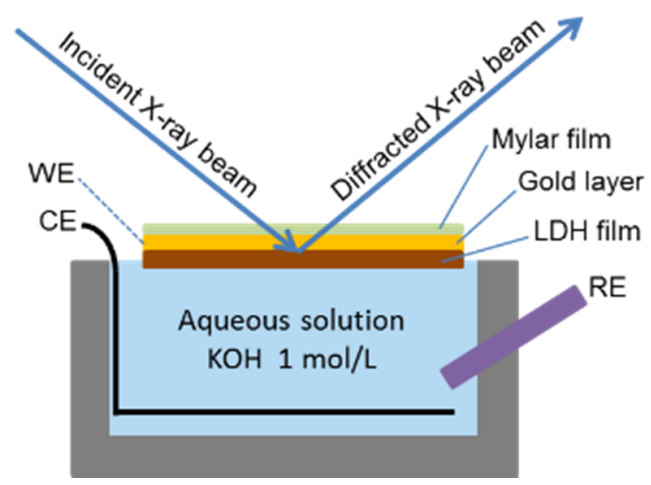

Figure 1. Scheme of in situ XRD analysis coupled with electrochemical measurements in KOH of a LDH thin film. WE: working electrode, CE: counter electrode and RE: reference electrode. 
The reversible variation of the interlayer-distance period during the redox reaction of $\mathrm{Ni}$ was evaluated by in situ recording of the XRD characteristic 003-peak of the LDH. A working electrode made of mylar film (4.5 $\mu \mathrm{m}$ thick) coated with a $100 \mathrm{~nm}$ gold layer and a thin film of LDH was immersed in an aqueous $\mathrm{KOH} 1 \mathrm{~mol} / \mathrm{L}$ solution (Figure 1). It underwent 40 polarization cycles to reflect the conditions of the ac-electrogravimetry experiments. The XRD measurements were recorded with a Panalytical Empyrean diffractometer operating at $45 \mathrm{kV}$ and $40 \mathrm{~mA}$ at room temperature, under $\mathrm{Cu} \mathrm{K} \alpha$ radiation $\left(\lambda=1.541 \AA\right.$ ) passing through a $15 \mathrm{~mm}$ mask with a $2^{\circ}$ slit. Scans were recorded at $0.45 \mathrm{~V}$ (reduced state of $\mathrm{LDH}$ ) and at $0.64 \mathrm{~V}$ (oxidized state of $\mathrm{LDH}$ ) from $8^{\circ}$ to $31^{\circ}(2 \theta)$ with a step of $0.026^{\circ}$ and a counting time of $600 \mathrm{~s} / \mathrm{step}$ to follow the 003 -peak of the LDH and a characteristic mylar peak taken as reference.

\section{RESULTS}

\section{Physical and Chemical Characterization of Ni/Fe-LDH}

PXRD analysis

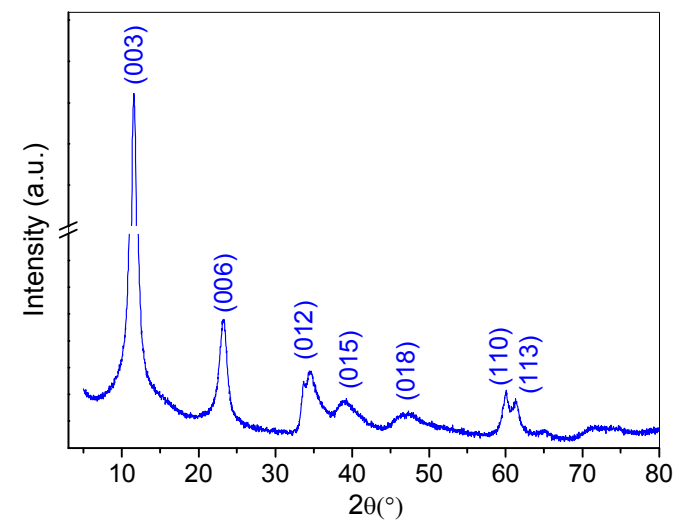

Figure 2. Powder XRD pattern of the Ni/Fe-LDH. 
The powder XRD pattern of Ni/Fe-LDH (Figure 2) is characteristic of the LDH structure. The diffraction peaks were indexed to a hexagonal lattice of rhombohedral 3R symmetry ${ }^{54}$ with three reflection groups:

(i) A set of basal (001) reflections corresponds to structural stacking along the c-axis, allowing determination of the basal distance $d$ (here $7.64 \AA$ ) that mainly depends upon the size of the intercalated species (anions and water molecules). ${ }^{55}$ Parameter c of the lattice equals $3 \mathrm{~d}(003)$ (here $22.92 \AA$ ).

(ii) The position of the (110) reflection is correlated to the lattice parameter a=2d (110) (here $3.08 \AA$ ), coinciding with the closest $\mathrm{M}-\mathrm{M}$ distance in the brucite-like layers.

(iii) The positions of the $(011) /(101)$ reflections common to hydrotalcite-like compounds, depending upon the polytype. These lattice parameters agree with those reported in the literature. ${ }^{55}$

FEG-SEM, EDX and XPS analyses.

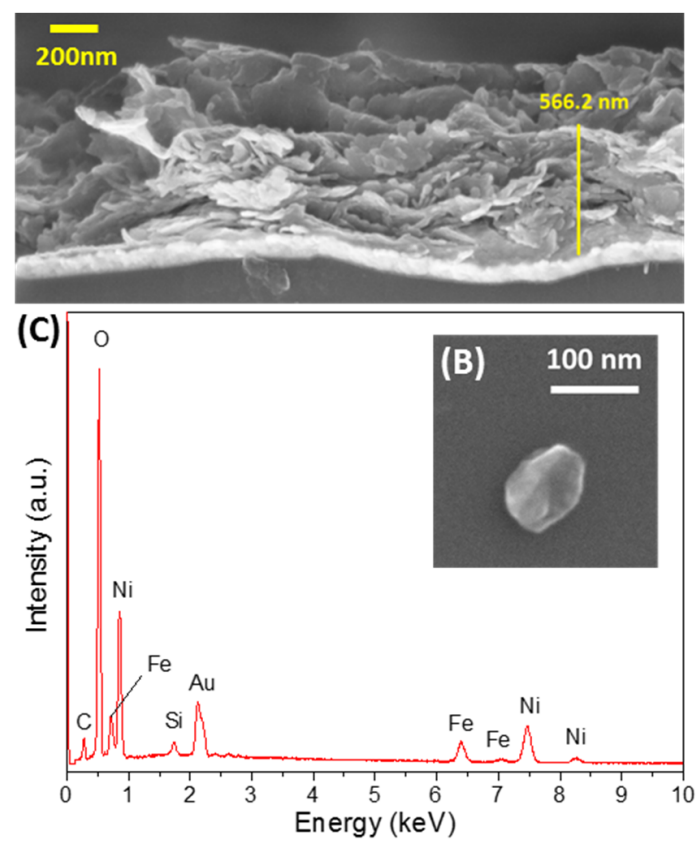

Figure 3. (A) FEG-SEM micrograph showing the cross-section of a gold-patterned quartz resonator modified with a thin LDH film, (B) FEG-SEM micrograph of a nanoplate of Ni/Fe-LDH 6/2 isolated on a silicon wafer, (C) EDX analysis of a thin film of Ni/Fe-LDH 6/2 deposited on the gold electrode of a quartz resonator. 
FEG-SEM micrographs show that synthesized LDH consists of nanoplates with particle size about $80 \mathrm{~nm}$ (Figure 3B), agreeing with literature data. ${ }^{49}$ The particle shown in Figure 3B is representative of the size distribution of the synthetized materials. The thickness of the film deposited onto the quartz resonator was measured by FEG-SEM (Figure 3A) at about $500 \mathrm{~nm}$ after deposition of $24.51 \mu \mathrm{g}$ of dried LDH powder on a $0.2 \mathrm{~cm}^{2}$ gold electrode.

A calibrated EDX analysis (Figure 3C) was done on a thin film of LDH dried on gold-coated quartz. The $\mathrm{Ni} / \mathrm{Fe}$ cationic ratio was $76 \% / 24 \%$ as expected during synthesis of the $\mathrm{LDH}$.

An XPS survey spectrum (Figure S1) shows that no contribution around $400 \mathrm{eV}$ was detected (N1s photopeak), confirming that no nitrate ions were was present in the $\mathrm{LDH}$ film after $\mathrm{NO}_{3}{ }^{-}$to $\mathrm{CO}_{3}{ }^{2-}$ anion exchange under air atmospheric.

TGA Analysis. TG analysis (Figure S2) combined with calibrated EDX analysis allowed determination of the $\mathrm{LDH}$ chemical formula as $\left[\mathrm{Ni}^{\mathrm{iI}}{ }_{0.76} \mathrm{Fe}^{\mathrm{III}}{ }_{0.24}(\mathrm{OH})_{2}\left(\mathrm{CO}_{3}{ }^{2-}\right)_{0.12}\right] .0 .5 \mathrm{H}_{2} \mathrm{O}$. Therefore, an LDH coating of $24.51 \mu \mathrm{g}$ - made by drop casting on the gold-coated quartz-consists of $0.22710^{-6} \mathrm{~mol} \mathrm{LDH}$ and thus of $1.0410^{17} \mathrm{Ni}$ sites. The anodic charge needed to oxidize all the Ni(II) into Ni(III) was thus 16.6 $\mathrm{mC}$.

EQCM Study.

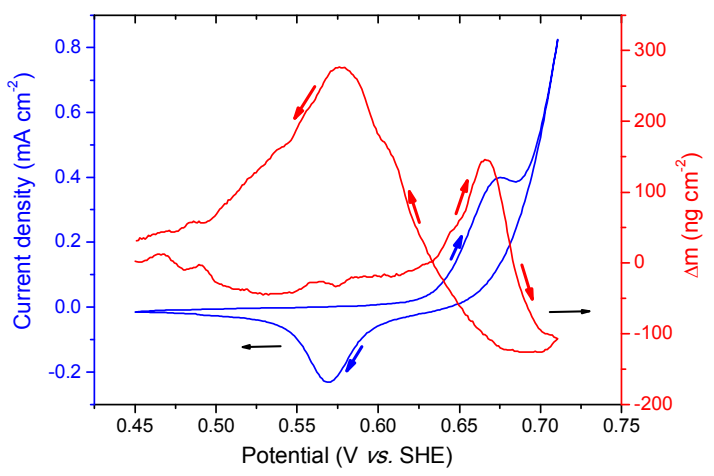


Figure 4. EQCM response during the $40^{\text {th }}$ potential scan of a Ni/Fe-LDH coated quartz resonator in $1 \mathrm{~mol} / \mathrm{L} \mathrm{KOH}$ at a $10 \mathrm{mV} / \mathrm{s}$ potential scan rate.

First, thin films of Ni/Fe-LDH underwent 40 polarization cycles (from $0.45 \mathrm{~V}$ to $0.71 \mathrm{~V}$ at $10 \mathrm{mV} / \mathrm{s}$ ) in an aqueous $\mathrm{KOH}$ solution of $1 \mathrm{~mol} / \mathrm{L}$ at $10 \mathrm{mV} / \mathrm{s}$. The current (I vs. E) and mass (m $v s$. E) responses were simultaneously recorded (Figure S3). After this preliminary treatment, reversibility of the mass variation was achieved (Figure S3). It is assumed that, during these 40 cycles, first interlayered carbonates were exchanged by hydroxyl ions (assuming that no water molecules are involved in the process $20 \%$ of the carbonates are exchanged) and then potassium cations were adsorbed onto the LDH external nanoplate surfaces (Figure S4A). Besides, the oxidation and reduction current peaks increased with the number of cycles (Figs. S3 and S4), indicating a rise in the number of redox-active Ni sites, probably due to some irreversibly oxidized Ni centres that enhance the material conductivity. ${ }^{56,57,58,59}$

Figure 4 shows the $40^{\text {th }}$ cycle after which the system reached a steady state regarding both current and mass versus applied potential. A broad cathodic peak (at $0.570 \mathrm{~V} v$ s. SHE) and a broad anodic peak (at $0.674 \mathrm{~V}$ vs. SHE) respectively indicate the reduction and oxidation of Ni sites into the Brucite-like layer of LDH material. ${ }^{14,60}$

The peak separation is $104 \mathrm{mV}$, comparable to the $98 \mathrm{mV}$ value found in the literature ${ }^{14}$ on platinum electrodes coated with Ni/Fe-LDH 6/2 denoting a slow-charge transfer. This phenomenon may be related to the known electronic transport within the LDH structure due to an electron hopping mechanism between adjacent nickel centres ${ }^{61}$ although Fe also plays a role in this hopping process ${ }^{14}$.

From the $40^{\text {th }}$ potential cycle, the charge is estimated by integration of the cathodic peak to be $0.27 \mathrm{mC}$, corresponding to $1.685 \times 10^{15}$ electroactive Ni atoms, or $1.62 \%$ of the Ni sites. Regarding the anodic peak, the concomitant $\mathrm{Ni}(\mathrm{II})$ and $\mathrm{H}_{2} \mathrm{O}$ oxidation reactions do not allow an accurate determination of the percentage of formed Ni(III) sites (Figure S4b). 
From the gravimetric response (Figure 4), it is obvious that the Ni/Fe-LDH film undergoes a mass increase followed by mass depletion during the anodic sweep, and a mass increase followed by a mass depletion during the cathodic sweep. According to the Ni(II) oxidation to Ni(III) within the LDH structure, the resulting modification in the redox state should induce $\mathrm{OH}^{-}$intercalation within the interlayer space. In addition to and agreeing with the electrocatalytic behaviour of the Ni/Fe-LDH for OER, the resulting $\mathrm{pH}$ variations at the interface, from $\mathrm{pH}>>\mathrm{pH}_{\mathrm{PZNC}}$ to $\mathrm{pH} \approx \mathrm{pH} \mathrm{PZNC}_{\mathrm{P} C}$, should induce modification of the charge at edge surfaces (Reaction (2.1)) and consequently in the electro-desorption/electrosorption of $\mathrm{K}^{+}$at external surfaces of the LDH nanosheets.

However, EQCM only provides an overview of the global transferred mass and cannot give precise information on the nature of the transferred species. It is challenging to deconvolute each species contribution into gravimetric and dynamic components with EQCM results, as the global cyclic electrogravimetry response is recorded at a certain scan rate, and at certain transfer kinetics. ${ }^{62-64}$ Therefore, $a c$-electrogravimetric measurements were carried out for this purpose.

Ac-Electrogravimetric Investigations. After 40 potential cycles from $0.45 \mathrm{~V}$ to $0.71 \mathrm{~V} v s$. SHE in $\mathrm{KOH} 1 \mathrm{~mol} / \mathrm{L}, a c$-electrogravimetry was carried out at different potentials, selected between the reduction and oxidation potentials of $\mathrm{Ni}$ (Figure 4), to gain insight into the (i) dynamic behaviour of each charged and uncharged species transfer at the interface, (ii) identification the nature of each transferred species, and (iii) evaluation of their respective concentration variation and kinetics as a function of the applied potential.

The data obtained at $0.65 \mathrm{~V} v s . \mathrm{SHE}$ is shown in Figure 5. The charge/potential TF, $\left.\frac{\Delta q}{\Delta E}\right|_{\text {exp }}{ }^{(\omega)}$ (derived from classical $\left.^{\frac{\Delta E}{\Delta I}}\right|_{\exp }{ }^{(\omega)}$, Eq. 3) is given for a clear representation of the ionic transfer. The fitting of the experimental charge/potential transfer function was performed using the theoretical TF, ${ }^{\left.\frac{\Delta q}{\Delta E}\right|_{t h} ^{\text {global }}}{ }^{(\omega)}$ (Eq. SI-9). It 


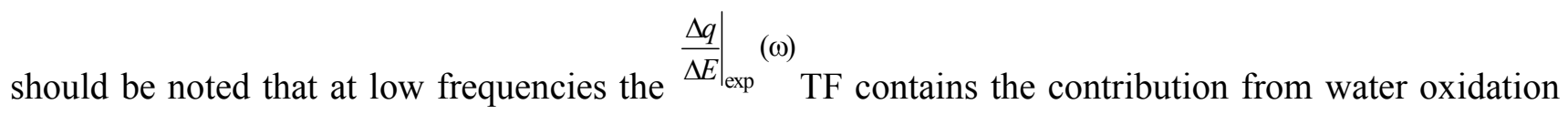
reaction (see Figure $\mathrm{S} 5$ ) which also participates to the overall impedance with $\mathrm{Z}_{\mathrm{par}}(\omega)$ determined using Eq. SI-8. For the sake of clarity, this contribution was removed in order to visualize only the ionic contri-

bution of the ${ }^{\left.\frac{\Delta q}{\Delta E}\right|_{\text {exp }} ^{\text {ion }}(\omega)}$ TF. The latter is fitted by using the theoretical expression given in Eq. SI-7. Both experimental and theoretical curves are shown in Figure 5A. A good agreement in terms of shape and frequencies is demonstrated.

Figure 5A shows two loops, one at high frequencies and another at low frequencies. They are attributed to the interfacial transfer of two different ionic species present in the electrolyte (Ion 1 and Ion 2). The kinetic parameter $\left(K_{i}\right)$ (Eq. SI-3) and the parameter related to the ease/difficulty of interfacial transfer $\left(G_{i}\right)$ (Eq. SI-4) for each ionic species were determined. This analysis permits to underline two ionic contributions, however, without any possibility to identify the involved ionic species at this step.

The same $K_{i}$ and $G_{i}$ values were then used in the fitting of the mass/potential transfer function, $\left.\frac{\Delta m}{\Delta E}\right|_{\exp }(\omega)$, by using the theoretical TF, $\left.\frac{\Delta m}{\Delta E}\right|_{t h}(\omega)$, given in Eq. SI-14. Figure 5B evidences a first loop appearing in the third quadrant at high frequency. It is noted that a loop in the third quadrant is characteristic of cation contribution or free solvent molecules in the same flux direction. ${ }^{52,53}$ Another contribution appears at intermediate frequencies in the third quadrant. Although small, a third contribution appears in the fourth quadrant at low frequency. Contributions in the fourth quadrant are characteristic of transfer of anions or of free solvent molecules in the same direction with the anions.

The fitting of the experimental data in Figure 5B evidences the nature of the three species, by the estimation of their atomic weight, $m_{i}$ parameter in Eq. SI-14. $\mathrm{K}^{+}$(Ion 1 in Figure $5 \mathrm{~A}$ ) is transferred at high frequencies and $\mathrm{OH}^{-}$(Ion 2 in Figure 5A) at low frequencies which confirms the configuration of two 
ions determined by the $\left.\frac{\Delta q}{\Delta E}\right|_{\exp } ^{\text {ion }}(\omega)$ SI-7), water molecules are transferred in the same direction with the cations.

(A)

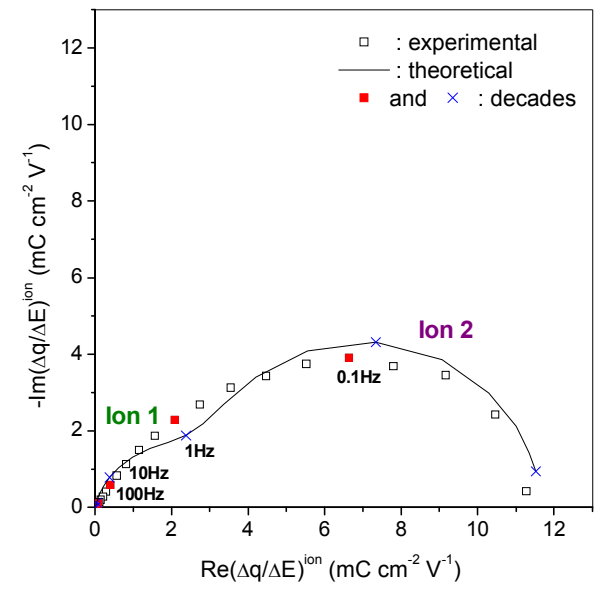

(C)

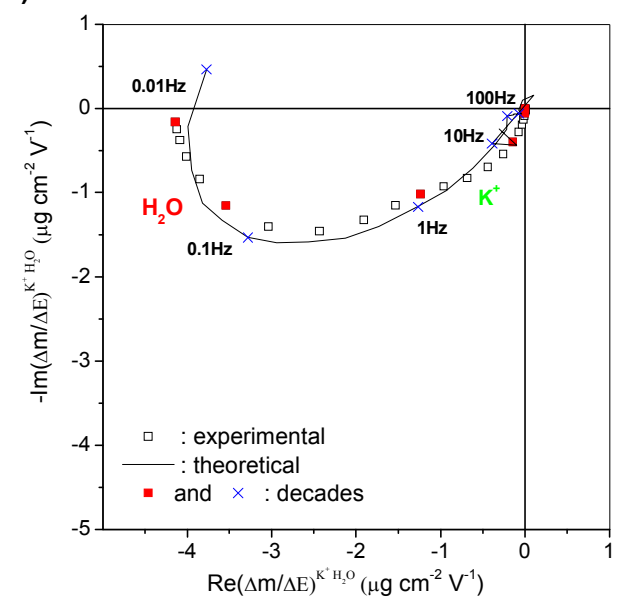

(B)

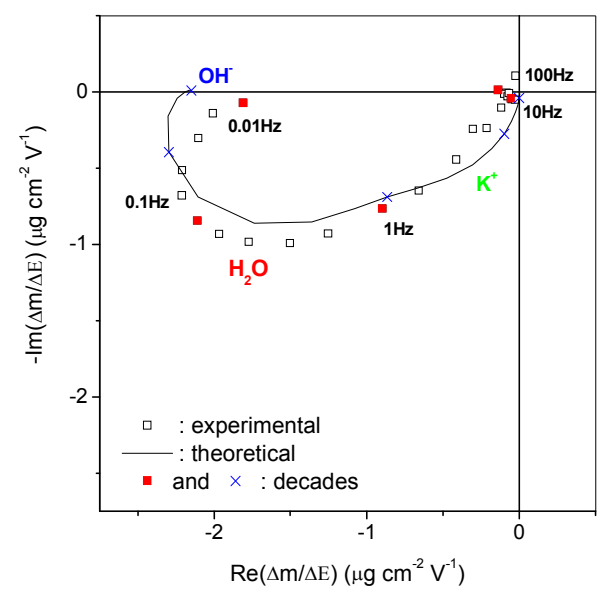

(D)

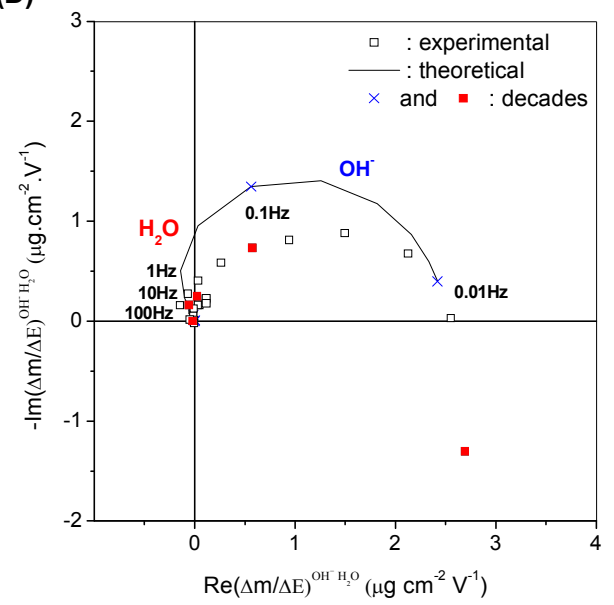

Figure 5. Experimental and fitted two main transfer functions $(\mathrm{A})(\Delta \mathrm{q} / \Delta \mathrm{E})^{\mathrm{ion}}(\omega)$ and $(\mathrm{B})(\Delta \mathrm{m} / \Delta \mathrm{E})(\omega)$, and two partial transfer functions $(\mathrm{C})(\Delta \mathrm{m} / \Delta \mathrm{E})^{\mathrm{K}+, \mathrm{H} 2 \mathrm{O}}(\omega)$ and $(\mathrm{D})(\Delta \mathrm{m} / \Delta \mathrm{E})^{\mathrm{OH}-\mathrm{H} 2 \mathrm{O}}(\omega)$. Ac-electrogravimetric measurements were performed on nano-Ni/Fe-LDH 6/2 in $\mathrm{KOH} 1 \mathrm{~mol} / \mathrm{L}$ electrolyte at $0.65 \mathrm{~V} v s$. SHE. Fitting parameters are presented in Table S1. 
It is emphasized that before validating this multi-species contribution enlisted above, several other configurations were tested in the fitting of the experimental data using the theoretical functions in Eqs SI-6 and SI-16. The strict criteria for attaining a conclusive match between experimental and theoretical data must be fulfilled for all the TFs and for the so-called partial TFs obtained by removing the contri-

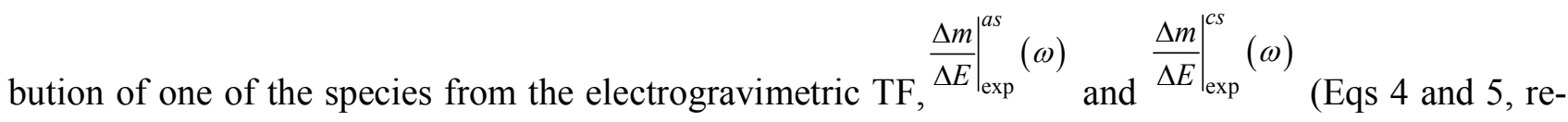
spectively), and analysing the residual response. The two experimental partial functions (Eqs 4 and 5) are fitted by the two theoretical partial TFs (Eqs SI-15 and SI-16) which resulted in a good agreement in terms of shape and frequencies (Figure 5C and Figure 5D). By this way, ambiguities concerning various possible models could be excluded, leading to the contributions of $\mathrm{K}^{+}$, free solvent and $\mathrm{OH}^{-}$as shown in Figure 5.

The same fitting procedure and validation control were used for all studied potentials from +0.575 $\mathrm{V}$ to $+0.675 \mathrm{~V}$, corresponding to the potential range where $\mathrm{Ni}$ oxidation and reduction reactions occur. The parameters $K_{i}, G_{i}$ and $R t_{i}=\frac{1}{F G_{i}}\left(\right.$ Eq. SI-4) were estimated for all of them. Based on the $K_{i}$ values (Figure $6 \mathrm{~A}$ ), the $\mathrm{K}^{+}$ion is the fastest of the three species exchanged at each potential, followed by $\mathrm{H}_{2} \mathrm{O}$ and $\mathrm{OH}^{-}$. The calculated $R t_{i}$ values (Eq. SI-4, Figure 6B) classify the transfer resistance of each species as follows: $\mathrm{Rt}_{\mathrm{i}}\left(\mathrm{OH}^{-}\right)>\mathrm{Rt}_{\mathrm{i}}\left(\mathrm{H}_{2} \mathrm{O}\right) \geqslant \mathrm{Rt}_{\mathrm{i}}\left(\mathrm{K}^{+}\right)$. This resistance of transfer is the highest for $\mathrm{OH}^{-}$therefore its kinetics is the slowest. This finding is in good agreement with the intercalation process of $\mathrm{OH}^{-}$into the $\mathrm{LDH}$ interlayer space. $\mathrm{K}^{+}$cations are faster and more easily transferred, especially at more anodic potentials (over $0.625 \mathrm{~V}$ vs. SHE), agreeing with the hypothesis of electro-adsorption onto more accessible sites like LDH edge surfaces. This will be discussed thereafter. 

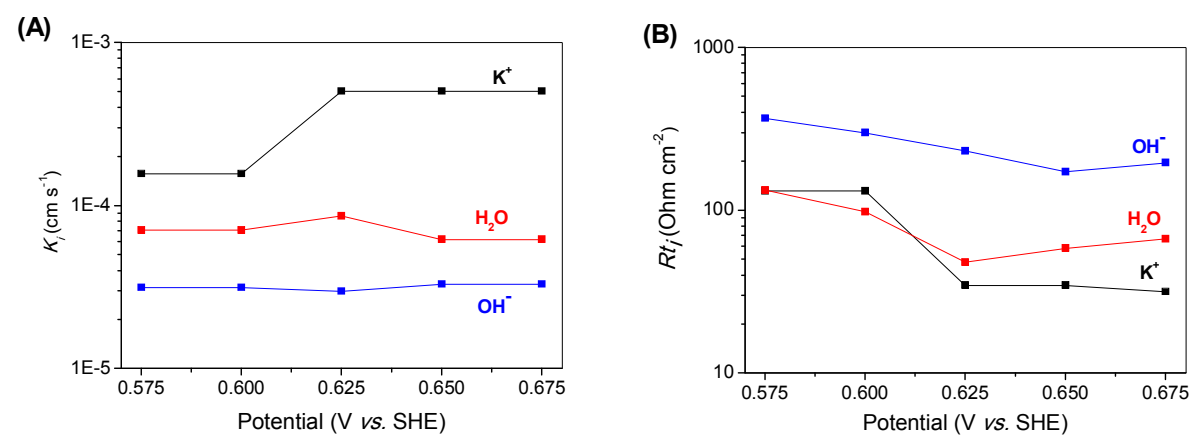

Figure 6. (A) Transfer kinetics rate, $K_{i}$, and (B) transfer resistance, $R t_{i}$, of $\mathrm{K}^{+}, \mathrm{H}_{2} \mathrm{O}$ and $\mathrm{OH}^{-}$as a function of applied potential in $\mathrm{KOH} 1 \mathrm{~mol} / \mathrm{L}$ solution.

The evolutions of the relative concentration per unit volume, $C_{i}-C_{o}$, and the mass per area unit, $m_{i}-m_{0}$ were determined from the $a c$-electrogravimetric data in the potential range from $0.575 \mathrm{~V}$ to 0.675 $\mathrm{V} v s$. SHE. The variation in concentration of the transferred species was estimated from the concentration/potential transfer function (Eq. SI-5) at low frequencies as shown below: ${ }^{63}$

$$
\left.\frac{\Delta C_{i}}{\Delta E}\right|_{\omega \rightarrow 0}=\int_{E_{0}}^{E_{1}}-\frac{G_{i}}{K_{i}} d E
$$

where $\mathrm{E}_{0}$ and $\mathrm{E}_{1}$ refer to two adjacent stationary potential values, at which the $a c$-electrogravimetry measurements have been performed. This concentration determination (Figure 7A), from $0.575 \mathrm{~V}$ to $0.675 \mathrm{~V}$ vs. SHE, showed that $\mathrm{K}^{+}$ions and $\mathrm{H}_{2} \mathrm{O}$ molecules are transferred from the $\mathrm{LDH}$ to the electrolyte whereas $\mathrm{OH}^{-}$ions are transferred from the electrolyte to the $\mathrm{LDH}$ when the Ni/Fe-LDH material is oxidized. The inverse processes occur during reduction. 
(A)

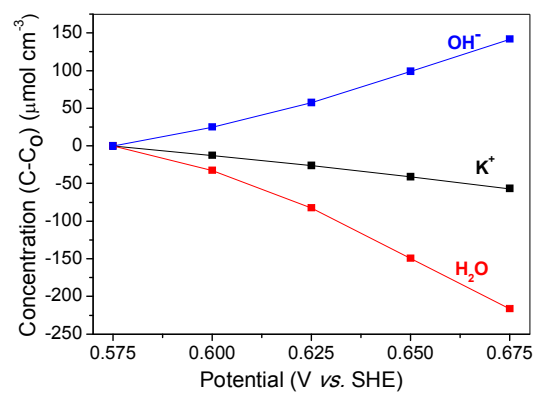

(B)

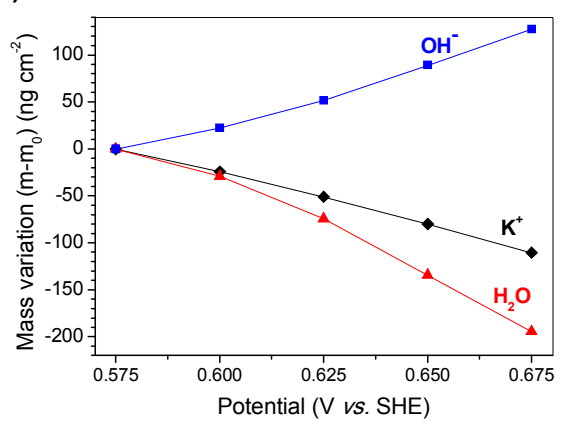

(C)

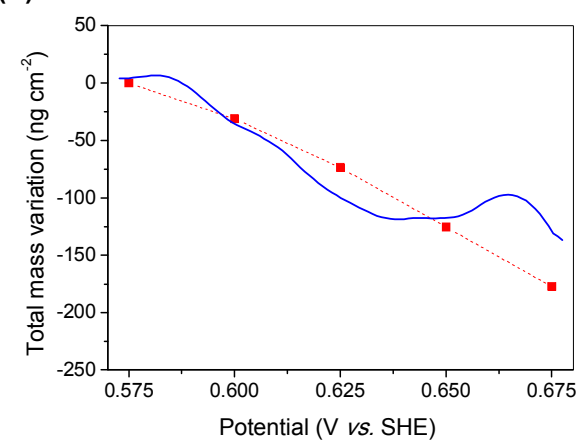

Figure 7. (A) Relative concentration change and (B) relative mass variation of $\mathrm{K}^{+}, \mathrm{H}_{2} \mathrm{O}$ and $\mathrm{OH}^{-}$in the thin film of Ni/Fe-LDH as a function of the applied potential in $\mathrm{KOH} 1 \mathrm{~mol} / \mathrm{L}$ solution, (C) comparison between the mass variation estimated with the $a c$-electrogravimetry (red squares) and that obtained directly from EQCM $(10 \mathrm{mV} / \mathrm{s})$ (full blue line).

From the $C_{i}-C_{o}$ values reported in Figure 7A, the mass variation per surface unit of each species for each potential can be calculated using equation 7 :

$$
m_{i}-m_{0}=\left(C_{i}-C_{o}\right) M_{i} d_{f}
$$

The results are reported in Figure 7B. The addition of these individual mass contributions leads to the "total mass variation re-calculated from the ac-electrogravimetry" (Figure 7C). Mass variations in the cathodic and anodic branches of classical EQCM response (Figure 4) were then averaged and compared 
to the total exchanged mass found with the $a c$-electrogravimetry (Figure $7 \mathrm{C}$ ). Both mass variations plotted in Figure $7 \mathrm{C}$ present the same behaviour with a change in the same order of magnitude. This finding evidences the accuracy of the developed model involving multi-species contribution with different proportion and time constants, at least for the studied potential range.

Note that for ac-electrogravimetry, a subsidiary irreversible reaction was considered for fitting of experimental data (Eqs SI-8 and SI-9). This side reaction was attributed to oxidation of the interlayered water molecules.

For a better insight regarding the sorption/interaction specific sites of each species identified $\left(\mathrm{K}^{+}\right.$, $\mathrm{H}_{2} \mathrm{O}$ and $\mathrm{OH}^{-}$), complementary analyses were performed on the $\mathrm{Ni} / \mathrm{Fe}-\mathrm{LDH}$, i.e. EDX and XPS analyses and in situ XRD under LDH film polarization.

EDX and XPS Analysis.

(A)

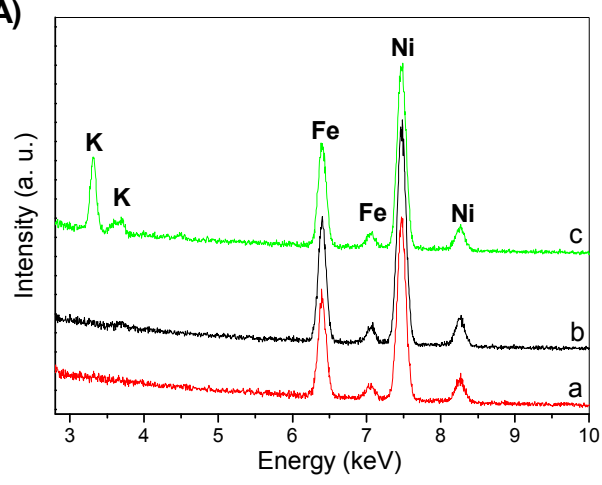

(B)

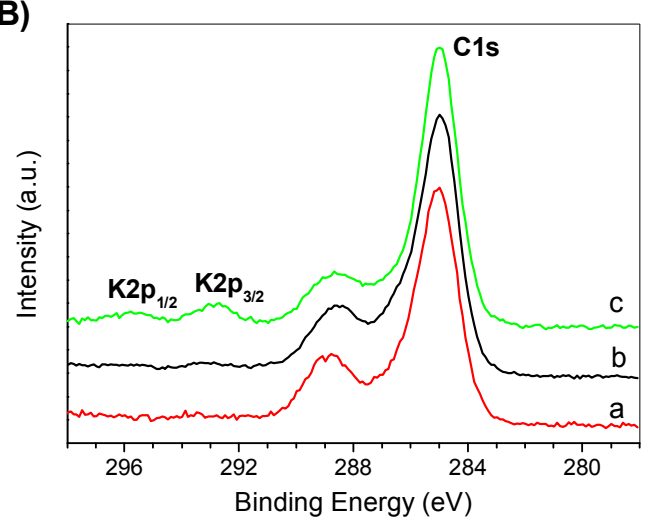

Figure 8. (A) EDX spectra; (B) K2p and C1s XPS spectra of (a) a thin film of dried LDH before immersion in $\mathrm{KOH} 1 \mathrm{~mol} / \mathrm{L}$, (b) after immersion in $\mathrm{KOH} 1 \mathrm{~mol} / \mathrm{L}$ and (c) after immersion and polarization in $\mathrm{KOH} 1 \mathrm{~mol} / \mathrm{L}$.

Electrogravimetric results have shown the concomitant anion and cation transfer. The former was attributed to the species contributing to the charge compensation due to a redox process involving Ni and 
the latter to a capacitive process. To confirm the electro-adsorption of cations (capacitive process) onto the LDH nanosheets, EDX and XPS analyses were done on a thin LDH film deposited on the gold electrode of a quartz resonator (i) before any experiment, (ii) after immersion in $\mathrm{KOH} 1 \mathrm{~mol} / \mathrm{L}$ for 40 minutes (about the same duration as the 40 cycles) and (iii) after 40 polarization cycles from $0.45 \mathrm{~V} v$ s. SHE to $0.71 \mathrm{~V} v s$. SHE at $10 \mathrm{mV} / \mathrm{s}$ in $\mathrm{KOH} 1 \mathrm{~mol} / \mathrm{L}$. Before EDX or XPS analyses, the LDH films in contact with $\mathrm{KOH} 1 \mathrm{~mol} / \mathrm{L}$ were rinsed in $\mathrm{NaOH} 10^{-4} \mathrm{M}$ to remove the $\mathrm{KOH}$ excess. The EDX and XPS spectra on Figure 8 do not show the presence of potassium ions in the LDH thin film either before or after 40 min immersion in $\mathrm{KOH} 1 \mathrm{~mol} / \mathrm{L}$ without polarization. But potassium was detected by both $\mathrm{EDX}$ and XPS analyses in the film affected by 40 cycles of Ni oxidation/reduction in $\mathrm{KOH} 1 \mathrm{~mol} / \mathrm{L}$. These findings demonstrate the electro-adsorption of potassium cations.

In situ XRD Analysis.
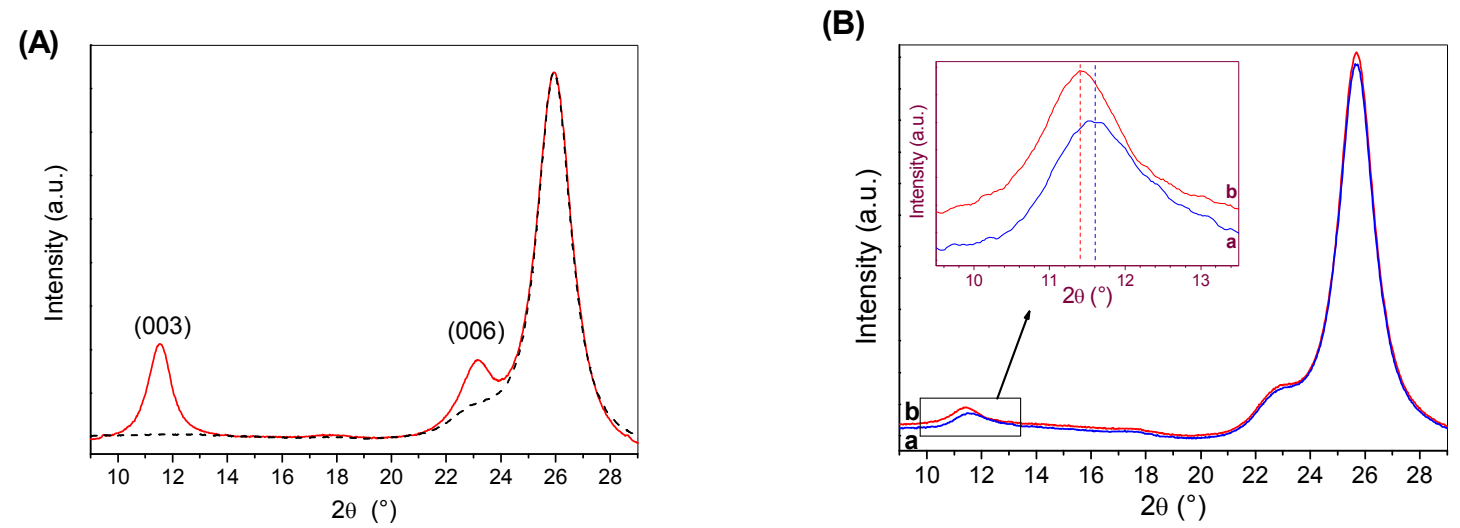

Figure 9. (A) XRD pattern of a mylar film coated with gold without (dashed line) and with (full line) a thin film of Ni/Fe-LDH. (B) In situ XRD patterns of a mylar film coated with gold and LDH under two polarizations: $0.450 \mathrm{~V} v s$. SHE (red line, a) and $0.640 \mathrm{~V} v s$. SHE (blue line, b). Insert: Magnification of the (003) peak under the two selected polarizations, $0.450 \mathrm{~V} v s$. SHE (a) and $0.640 \mathrm{~V} v s$. SHE (b). 
For a better understanding of the influence of the electrochemical treatment undergone by LDH particles in aqueous $\mathrm{KOH} 1 \mathrm{~mol} / \mathrm{L}$, XRD analysis were done on $\mathrm{LDH}$ particles deposited on a gold-based electrode (Figure 1), consisting in a gold-coated mylar film. The experiments were run in the range from 9 to $29^{\circ}$ in $2 \theta$.

Analyses were first conducted on (i) gold-coated mylar film (Figure 9A, black dashed line) and (ii) dried LDH particles deposited on gold-coated mylar film (Figure 9A, red full line). The cubic ${ }^{65}$ gold is illustrated by the small broad band at $2 \theta=23^{\circ}$ and the diffraction peaks at $2 \theta=26^{\circ}$. The position of the (003) and (006) peaks of LDH is clearly seen around $11.5^{\circ}$ and $23^{\circ}(2 \theta)$, respectively.

Analyses were then conducted in $\mathrm{KOH} 1 \mathrm{~mol} / \mathrm{L}$ solution after 40 polarization cycles, successively (i) at $0.640 \mathrm{~V} v s$. SHE (oxidation of some Ni(II) sites, Figure 9B-a, blue line) and (ii) $0.450 \mathrm{~V} v s$. SHE (reduction of $\mathrm{Ni}(\mathrm{III})$, Figure 9B-b, red line); these analyses were repeated five times. In the range from $22^{\circ}$ to $24^{\circ}$ in $2 \theta$, the $(006)$ peaks present a rather low signal-to-noise ratio due to the substrate (Figure 9A). The characteristic gold diffraction peak at $2 \theta=26^{\circ}$ remained in the same position regardless of the potential, and could be used as an internal reference for investigating the (003) LDH diffraction-peak behaviour; i.e. the evolution of basal distance versus applied potential.

Insert of Figure 9B shows the XRD spectrum between $9^{\circ}$ and $15^{\circ}$ in $2 \theta$. Evaluation of the $003-$ period variation in solution is possible through the shift in position of the LDH (003) peak. Table 1 shows the shift in position of the 003-period for five successive experiments. 


\section{Table 1. In situ DRX Measurements.}

Basal spacing obtained after five successive polarizations at $0.450 \mathrm{~V}(\mathrm{Ni}$ (III) reduction) and at $0.640 \mathrm{~V}$ (Ni(II) oxidation) in $\mathrm{KOH} 1 \mathrm{~mol} / \mathrm{L}$.

\begin{tabular}{ccccc}
\hline $\begin{array}{c}\text { Experiment } \\
\text { number }\end{array}$ & $\begin{array}{c}\text { Applied po- } \\
\text { tential (V) }\end{array}$ & Basal spacing $(\AA)$ & Error $(\AA)$ & $\begin{array}{c}\text { Basal spacing } \\
\text { variation }(\AA)\end{array}$ \\
\hline 1 & 0.450 & 7.4280 & 0.0239 & --- \\
2 & 0.640 & 7.3619 & 0.0444 & -0.0661 \\
3 & 0.450 & 7.4426 & 0.0250 & 0.0807 \\
4 & 0.640 & 7.3855 & 0.0449 & -0.0571 \\
5 & 0.450 & 7.4532 & 0.0270 & 0.0677 \\
\hline
\end{tabular}

The Ni oxidation at $0.640 \mathrm{~V}$ (experiments 2 and 4 in Table 1) leads to a decrease in the 003-period, whereas the Ni reduction at $0.450 \mathrm{~V}$ (experiments 3 and 5) leads to a 003 -period increase. The redox reactions involve a local withdrawal/expansion of d-spacing from the average value.

\section{DISCUSSION}

Investigation of the electrochemical behaviour of nano-Ni/Fe-LDH 6/2 particles in $\mathrm{KOH} 1 \mathrm{~mol} / \mathrm{L}$ through ac-electrogravimetry indicates pseudocapacitive LDH properties of a mixed cation and anion exchanger. Figure 10 summarizes all the steps and reactions occurring during the cycling potential imposed to the LDH film composed of nanosheets of Ni/Fe-LDH deposited on the Au electrode. Two different ionic species with different kinetics of transfer were detected, their contribution being attributed to a redox process due to $\mathrm{Ni}$ and a capacitive process ascribed to $\mathrm{K}^{+}$. The later result is in good agreement with the results already reported on $\mathrm{LDH}^{1}$ and $\mathrm{LDH}$ based structures ${ }^{66,67}$. 


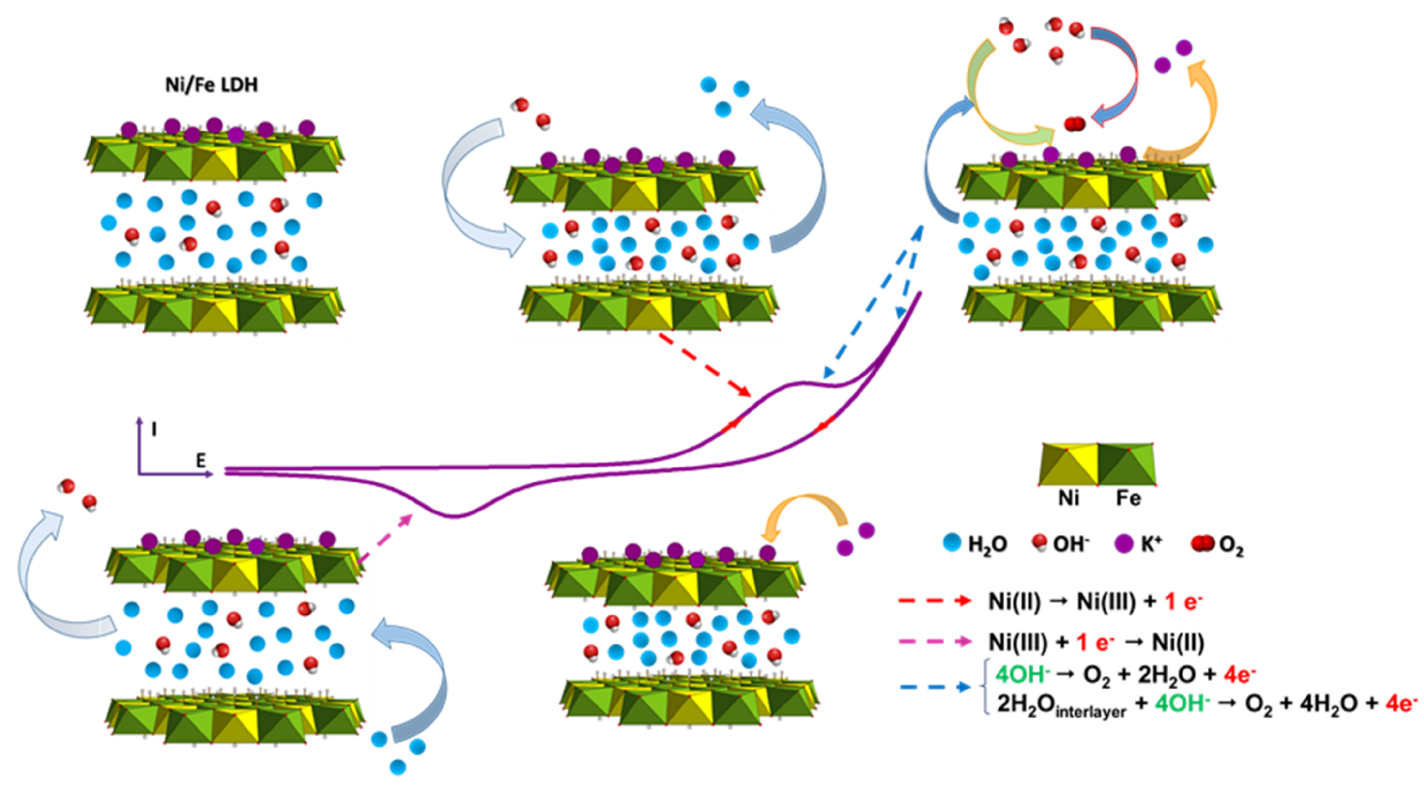

Figure 10. Scheme showing the various electron and species (ions and water) transfers during $\mathrm{Ni} / \mathrm{Fe}$ polarization in $\mathrm{KOH} 1 \mathrm{~mol} / \mathrm{L}$.

Regarding the faradic process, the positive charge of the Brucite-like layer increases due to the oxidation of some $\mathrm{Ni}$ (II) sites to $\mathrm{Ni}(\mathrm{III})$; it is balanced by intercalation of $\mathrm{OH}^{-}$anions in the $\mathrm{LDH}$ interlayer space. The intercalation of one $\mathrm{OH}^{-}$anion and the expulsion of 1.5 interlayered water molecules are observed (Figure 7A) according to the following reaction:

$\left[\mathrm{Ni}_{6}{ }_{6} \mathrm{Fe}^{\mathrm{III}} 2(\mathrm{OH})_{16-\mathrm{c}}(\mathrm{OK})_{\mathrm{c}}\right]^{2+}\left[(\mathrm{OH})_{2}\right]^{2-}, 4 \mathrm{H}_{2} \mathrm{O}+\mathrm{x} \mathrm{OH}^{-} \leftrightarrows$

$\left[\mathrm{Ni}_{6-\mathrm{x}} \mathrm{Ni}_{\mathrm{x}}{ }_{\mathrm{III}} \mathrm{Fe}^{\mathrm{III}}{ }_{2}(\mathrm{OH})_{16-\mathrm{c}}(\mathrm{OK})_{\mathrm{c}}\right]^{(2+\mathrm{x})+}\left[(\mathrm{OH})_{2+\mathrm{x}}\right]^{(2+\mathrm{x})-},(4-1.5 \mathrm{x}) \mathrm{H}_{2} \mathrm{O}+1.5 \mathrm{x} \mathrm{H} \mathrm{H}_{2} \mathrm{O}+\mathrm{xe}-$

By analogy with observations on polymer films, ${ }^{55}$ this phenomenon can be related to free water transfer caused by structural modifications of the electroactive film, leading to contraction of the LDH layer. EXAFS analysis of polarized Ni/Fe-LDH 6/2 electrodes indicates that both $\mathrm{Ni}-\mathrm{O}$ and $\mathrm{Fe}-\mathrm{O}$ distances decrease to $\sim 1.9 \AA$ (from d $(\mathrm{Ni}-\mathrm{O})=2.06 \AA$ and $\mathrm{d}(\mathrm{Fe}-\mathrm{O})=2.01 \AA$ in an unpolarized electrode $).{ }^{60}$ The Ni-O bond shortening is consistent with an increase in the Ni oxidation state. ${ }^{68}$ Fe-bond contraction 
is plausible as the lattice contraction accompanying $\mathrm{Ni}$ oxidation imposes a stronger ligand field on the $\mathrm{Fe}(\mathrm{III})$ centres, inducing crossover from a high-spin electronic structure to a low-spin state. ${ }^{68} \mathrm{Fe}-\mathrm{O}$ distances of $\sim 1.9 \AA$ are consistent with low-spin Fe(III). ${ }^{69}$

Moreover, by analogy to cationic clay minerals, the nature and strength of the forces affecting a water molecule depend on its position within the pore space, here the distance to the LDH surfaces. ${ }^{70}$ In clay minerals, crystalline swelling is controlled by a balance between strong attraction and repulsion ${ }^{71,72}$ forces, and is more easily modelled by considering the potential energies of attraction and repulsion. ${ }^{73}$ Again by analogy to cationic clay minerals, the potential attraction energy should be electrostatic, dominantly arising from Coulombic attraction between the positive surface-charge sites caused by isomorphous substitution and the negative charge of interlayer anions. Van der Waals interaction between adjacent layers may also contribute to the total potential attraction energy. The potential repulsion energy comes from the partial hydration potential energy of interlayer anions and, to a lesser degree, of positive surface-charge sites. By analogy to the swelling stages investigated by Lal and Shukla ${ }^{74}$ the charge increase due to $\mathrm{Ni}(\mathrm{II})$ to $\mathrm{Ni}(\mathrm{III})$ oxidation reinforces Coulombic charges; the $\mathrm{H}_{2} \mathrm{O}$ de-intercalation is opposed by the electrostatic attraction between anions and positively charged layers of the LDH. During the cathodic sweep, anion hydration is more important than the electroactive attraction between anions and the positively charged layer. In this way, ac-electrogravimetric measurements agree with in situ XRD under polarization. Redox reactions cause local withdrawal/expansion phenomena in agreement with the successive exclusion and insertion of interlayered water molecules in $\mathrm{d}$ spacing. By analogy to cationic clay minerals, these results confirm those provided by different authors. ${ }^{75,76,77}$

In situ XRD under polarization has especially contributed to our understanding of LDH hydration during cyclic oxidation/reduction. In addition, $a c$-electrogravimetric experiments revealed an irreversible 
redox reaction that was attributed to the $\mathrm{O}_{2}$ evolution reaction due to the oxidation of (i) interfacial $\mathrm{OH}^{-}$ and (ii) interlayered water molecules, for the latter according to the following reaction:

$$
\begin{aligned}
& {\left[\mathrm{Ni}_{6-\mathrm{x}}^{\mathrm{II}} \mathrm{Ni}_{x}{ }_{x} \mathrm{Fe}^{\mathrm{III}}{ }_{2}(\mathrm{OH})_{16-\mathrm{c}}(\mathrm{OK})_{\mathrm{c}}\right]^{(2+\mathrm{x})+}\left[(\mathrm{OH})_{2+\mathrm{x}}\right]^{(2+\mathrm{x})},(4-2 \mathrm{x}) \mathrm{H}_{2} \mathrm{O}+2 \mathrm{z} \mathrm{OH}^{-} \rightarrow} \\
& {\left[\mathrm{Ni}^{\mathrm{II}}{ }_{6-\mathrm{x}} \mathrm{Ni}^{\mathrm{III}}{ }_{x} \mathrm{Fe}^{\mathrm{IIII}}{ }_{2}(\mathrm{OH})_{16-\mathrm{c}}(\mathrm{OK})_{\mathrm{c}}\right]^{(2+\mathrm{x})+}\left[(\mathrm{OH})_{2+\mathrm{x}}\right]^{(2+\mathrm{x})},(4-2 \mathrm{x}-\mathrm{z}) \mathrm{H}_{2} \mathrm{O}+2 \mathrm{z} \mathrm{H}_{2} \mathrm{O}+\mathrm{z} / 2 \mathrm{O}_{2}+2 \mathrm{z} \mathrm{e}^{-}}
\end{aligned}
$$

During the anodic sweep, the catalysed oxygen evolution reaction caused a decrease of the interfacial $\mathrm{pH}$ and allowed cation desorption from the negatively charged external surface of the LDH nanoplates. During the backward cathodic scan, the current cancelled and the interfacial $\mathrm{pH}$ became equal to that of the bulk solution, allowing cation sorption on the external negatively charged surface of the material. This phenomenon was confirmed by EDX and XPS analyses (K detection), in agreement with the following reaction:

$\left[\mathrm{Ni}_{6-\mathrm{x}} \mathrm{Ni}_{\mathrm{x}} \mathrm{Fe}^{\mathrm{IIII}}{ }_{2}(\mathrm{OH})_{16-\mathrm{c}}(\mathrm{OH})_{\mathrm{c}}\right]^{(2+\mathrm{x})+}\left[(\mathrm{OH})_{2+\mathrm{x}}\right]^{(2+\mathrm{x})-},(4-2 \mathrm{x}-\mathrm{z}) \mathrm{H}_{2} \mathrm{O}+\mathrm{c} \mathrm{K}^{+}+\mathrm{c} \mathrm{OH}^{-} \leftrightarrows$

$\left[\mathrm{Ni}_{6-\mathrm{x}} \mathrm{Ni}_{\mathrm{x}} \mathrm{Fe}^{\mathrm{IIII}}{ }_{2}(\mathrm{OH})_{16-\mathrm{c}}(\mathrm{OK})_{\mathrm{c}}\right]^{(2+\mathrm{x})+}\left[(\mathrm{OH})_{2+\mathrm{x}}\right]^{(2+\mathrm{x})-},(4-2 \mathrm{x}-\mathrm{z}) \mathrm{H}_{2} \mathrm{O}+\mathrm{c} \mathrm{H} \mathrm{H}_{2} \mathrm{O}$

When the oxygen evolution reaction stops, water molecules should diffuse into the interlayer space of the Ni-Fe LDH.

Related to cation transfer, $\mathrm{K}^{+}$cations were shown to be faster and more easily transferred, especially at more anodic potentials, agreeing with the hypothesis of electro-adsorption onto more accessible sites like edge surfaces once the $\mathrm{pH}$ decreases and tends to the $\mathrm{pH}_{\mathrm{PZNC}}$ value during the anodic sweep. Compared to cationic clay minerals whose edge surface can be reversibly deprotonated ${ }^{29,78}$, the positively charged LDH basal surface should render the $\mathrm{H}$ of the $\equiv \mathrm{M}-\mathrm{OH}$ groups more labile, which should be amplified by oxidation of the basal Ni(II). Thus, in the case of LDH, both edge surfaces and external basal surfaces are cation sorption sites.

\section{CONCLUSIONS}


For the first time, both electrochemical reactions and related ionic and water transfers in $\mathrm{Ni} / \mathrm{Fe}-$ LDH 6/2 via electro-gravimetric definition were investigated. Experiments were conducted under polarization in $\mathrm{KOH} 1 \mathrm{~mol} / \mathrm{L}$, to differentiate the associated specific transfer sites, i.e. adsorption sites onto both edge and external basal surfaces, and intercalation sites in the interlayer space. For a better insight, complementary techniques included EDX and XPS analyses and in-situ XRD under polarization were performed.

Reversible Ni oxidation and reduction were observed using EQCM with a slow anion transfer. After 40 potential cycles, the film mass variation was reversible, regardless of complexity. Ac-electrogravimetry identified the nature of the charged and uncharged species, as well as the kinetics rate $\left(\mathrm{K}\left(\mathrm{K}^{+}\right)>\mathrm{K}\left(\mathrm{H}_{2} \mathrm{O}\right)>\mathrm{K}\left(\mathrm{OH}^{-}\right)\right)$and facility of transfer, exchanged concentration and exchanged mass for each species at different polarizations. It demonstrated the nano-Ni/Fe-LDH pseudocapacitive properties of a mixed cation $\left(\mathrm{K}^{+}\right)$and anion $\left(\mathrm{OH}^{-}\right)$exchanger. Ni redox reaction is responsible for anion intercalation/de-intercalation into/from the interlayer spacing. In the same time, the net swellability is determined by the balance achieved between modulated the positive layer charge and the negative charge of interlayer compensating anions. This mechanism was further demonstrated by in-situ XRD analyses. Concomitantly, the $\mathrm{pH}$ variation at the coated interface, due to a catalysed oxygen evolution reaction, caused cation electro-adsorption/desorption on the external surfaces. This was also confirmed by EDX and XPS analyses.

\section{ASSOCIATED CONTENT}

\section{Supporting Information.}

$A c$-electrogravimetry theorical part and data analysis. 
XPS survey spectrum, TGA curve, IV responses obtained during the 40 first potential cycles. Table showing the estimated values of parameters extracted from the fitting results of $a c$-electrogravimetry measurements. (PDF)

This material is available free of charge via the Internet at http://pubs.acs.org."

\section{AUTHOR INFORMATION}

\section{Corresponding Authors}

Stéphanie BETELU: s.betelu@brgm.fr

Catherine DEBIEMME-CHOUVY: catherine.debiemme-chouvy@sorbonne-universite.fr

\section{ORCID}

Stéphanie Betelu: 0000-0002-3050-1530

Catherine Debiemme-Chouvy: 0000-0001-7171-6039

\section{Author Contributions}

The manuscript was written through contributions of all authors. All authors have approved the final version of the manuscript.

\section{Funding Sources}

Financial support was provided by the BRGM and the Labex Matisse from Sorbonne University.

\section{ACKNOWLEDGMENT}

The authors thank Ms. Françoise Pillier for the SEM-FEG observations and Cédric Roosz for providing the schematic representation of the LDH structure. Dr H.M. Kluijver checked and edited the final English manuscript. 


\section{REFERENCES}

1. Taviot-Gueho, C.; Vialat, P.; Leroux, F.; Razzaghi, F.; Perrot, H.; Sel, O.; Jensen, N. D.; Nielsen, U. G.; Peulon, S.; Elkaim, E.; Mousty, C., Dynamic Characterization of Inter- and Intralamellar Domains of Cobalt-Based Layered Double Hydroxides upon Electrochemical Oxidation. Chemistry of Materials 2016, 28, 7793-7806.

2. Cavani, F.; Trifiro, F.; Vaccari, A., Hydrotalcite-type anionic clays: preparation, properties and applications. Catalysis Today 1991, 11, 173-301.

3. Vaccari, A., Preparation and catalytic properties of cationic and anionic clays. Catalysis Today 1998, $41,53-71$.

4. Cao, Z.; Li, B.; Sun, L.; Li, L.; Xu, Z. P.; Gu, Z., 2D Layered Double Hydroxide Nanoparticles: Recent Progress toward Preclinical/Clinical Nanomedicine. Small Methods 2019, 1900343.

5. Arrabito, G.; Bonasera, A.; Prestopino, G.; Orsini, A.; Mattoccia, A.; Martinelli, E.; Pignataro, B.; Medaglia, P. G., Layered Double Hydroxides: A Toolbox for Chemistry and Biology. Crystals 2019, 9,361 .

6. Bernardo, M. P.; Guimaraes, G. G. F.; Majaron, V. F.; Ribeiro, C., Controlled Release of Phosphate from Layered Double Hydroxide Structures: Dynamics in Soil and Application as Smart Fertilizer. Acs Sustainable Chemistry \& Engineering 2018, 6, 5152-5161.

7. Dennis, R. V.; Patil, V.; Andrews, J. L.; Aldinger, J. P.; Yadav, G. D.; Banerjee, S., Hybrid nanostructured coatings for corrosion protection of base metals: a sustainability perspective. Materials Research Express 2015, 2, 032001.

8. Guo, L.; Wu, W.; Zhou, Y.; Zhang, F.; Zeng, R.; Zeng, J., Layered double hydroxide coatings on magnesium alloys: A review. Journal of Materials Science \& Technology 2018, 34, 1455-1466. 
9. Zumreoglu-Karan, B.; Ay, A. N., Layered double hydroxides - multifunctional nanomaterials. Chemical Papers 2012, 66, 1-10.

10. Miyata, S., Anion exchange properties of hydrotalcite-like compounds. Clays and Clay Minerals 1983, 31, 305-311.

11. Goh, K. H.; Lim, T. T.; Dong, Z., Application of layered double hydroxides for removal of oxyanions: A review. Water Research 2008, 42, 1343-1368.

12. Delorme, F.; Seron, A.; Vergnaud, B.; Galle-Cavalloni, P.; Jean-Prost, V.; Manguin, J., Evidence of the influence of the cationic composition on the anionic affinity of layered double hydroxides. Journal of Materials Science 2013, 48, 5273-5279.

13. Ardau, C.; Frau, F.; Lattanzi, P., New data on arsenic sorption properties of Zn-Al sulphate layered double hydroxides: Influence of competition with other anions. Applied Clay Science 2013, 80-81, 1-9.

14. Scavetta, E.; Vlamidis, Y.; Posati, T.; Nocchetti, M.; Tonelli, D., Effect of the Synthesis Route and Fe Presence on the Redox Activity of Ni in Layered Double Hydroxides. Chemelectrochem 2016, 3, $1320-1328$.

15. Lal, M.; Howe, A. T., Studies of zinc-chromium hydroxy salts. 2. Composite anion conductors of pressed disks of $\mathrm{Zn}_{2} \mathrm{Cr}(\mathrm{OH})_{6} \mathrm{X} . \mathrm{nH}_{2} \mathrm{O}$, where $\mathrm{X}^{-}=\mathrm{F}^{-}, \mathrm{Cl}^{-}, \mathrm{Br}^{-}, \mathrm{I}^{-}, \mathrm{NO}_{3}{ }^{-}$and $1 / 2 \mathrm{CO}_{3}{ }^{2-}$. Journal of Solid State Chemistry 1981, 39, 377-386.

16. Xu, L.; Lin, Y. Q.; Chen, X.; Lu, Y. L.; Yang, W. S., Electrodeposition of Platinum Nanoparticles on MgAl-layered Double Hydroxide Modified Indium Tin Oxide Electrode for Electrochemical Glucose Biosensor. Chemical Journal of Chinese Universities-Chinese 2016, 37, 442-447.

17. Desigaux, L.; Ben Belkacem, M.; Richard, P.; Cellier, J.; Leone, P.; Cario, L.; Leroux, F.; Taviot-Gueho, C.; Pitard, B., Self-assembly and characterization of layered double hydroxide/DNA hybrids. Nano Letters 2006, 6, 199-204. 
18. Roto, R.; Yamagishi, A.; Villemure, G., Electrochemical quartz crystal microbalance study of mass transport in thin film of a redox active Ni-Al-Cl layered double hydroxide. Journal of Electroanalytical Chemistry 2004, 572, 101-108.

19. Scavetta, E.; Ballarin, B.; Corticelli, C.; Gualandi, I.; Tonelli, D.; Prevot, V.; Forano, C.; Mousty, C., An insight into the electrochemical behavior of $\mathrm{Co} / \mathrm{Al}$ layered double hydroxide thin films prepared by electrodeposition. Journal of Power Sources 2012, 201, 360-367.

20. Roto, R.; Villemure, G., Mass transport in thin films of $\mathrm{Fe}(\mathrm{CN}) 6^{4-}$ exchanged Ni-Al layered double hydroxide monitored with an electrochemical quartz crystal microbalance. Journal of Electroanalytical Chemistry 2006, 588, 140-146.

21. Guo, X. X.; Zhang, F. Z.; Evans, D. G.; Duan, X., Layered double hydroxide films: synthesis, properties and applications. Chemical Communications 2010, 46, 5197-5210.

22. Su, L. H.; Zhang, X. G.; Mi, C. H.; Liu, Y., Insights into the electrochemistry of layered double hydroxide containing cobalt and aluminum elements in lithium hydroxide aqueous solution. Journal of Power Sources 2008, 179, 388-394.

23. Bradbury, M. H.; Baeyens, B., A mechanistic description of $\mathrm{Ni}$ and $\mathrm{Zn}$ sorption on Namontmorillonite .2. Modelling. Journal of Contaminant Hydrology 1997, 27, 223-248.

24. Bradbury, M. H.; Baeyens, B., Modelling the sorption of $\mathrm{Zn}$ and Ni on Ca-montmorillonite. Geochimica Et Cosmochimica Acta 1999, 63, 325-336.

25. Avena, M. J.; De Pauli, C. P., Proton adsorption and electrokinetics of an Argentinean montmorillonite. Journal of Colloid and Interface Science 1998, 202, 195-204.

26. Tombacz, E.; Szekeres, M., Colloidal behavior of aqueous montmorillonite suspensions: the specific role of $\mathrm{pH}$ in the presence of indifferent electrolytes. Applied Clay Science 2004, 27, 75-94. 
27. Tournassat, C.; Ferrage, E.; Poinsignon, C.; Charlet, L., The titration of clay minerals II. Structurebased model and implications for clay reactivity. Journal of Colloid and Interface Science 2004, 273, 234-246.

28. Tournassat, C.; Neaman, A.; Villieras, F.; Bosbach, D.; Charlet, L., Nanomorphology of montmorillonite particles: Estimation of the clay edge sorption site density by low-pressure gas adsorption and AFM observations. American Mineralogist 2003, 88, 1989-1995.

29. Tournassat, C.; Davis, J. A.; Chiaberge, C.; Grangeon, S.; Bourg, I. C., Modeling the Acid-Base Properties of Montmorillonite Edge Surfaces. Environmental Science \& Technology 2016, 50, 1343613445.

30. Tournassat, C.; Bizi, M.; Braibant, G.; Crouzet, C., Influence of montmorillonite tactoid size on Na-Ca cation exchange reactions. Journal of Colloid and Interface Science 2011, 364, 443-454.

31. Hadi, J.; Tournassat, C.; Ignatiadis, I.; Greneche, J. M.; Charlet, L., Modelling CEC variations versus structural iron reduction levels in dioctahedral smectites. Existing approaches, new data and model refinements. Journal of Colloid and Interface Science 2013, 407, 397-409.

32. Song, F.; Hu, X. L., Exfoliation of layered double hydroxides for enhanced oxygen evolution catalysis. Nature Communications 2014, 5 .

33. Gong, M.; Li, Y. G.; Wang, H. L.; Liang, Y. Y.; Wu, J. Z.; Zhou, J. G.; Wang, J.; Regier, T.; Wei, F.; Dai, H. J., An Advanced Ni-Fe Layered Double Hydroxide Electrocatalyst for Water Oxidation. Journal of the American Chemical Society 2013, 135, 8452-8455.

34. Lee, Y.; Choi, J. H.; Jeon, H. J.; Choi, K. M.; Lee, J. W.; Kang, J. K., Titanium-embedded layered double hydroxides as highly efficient water oxidation photocatalysts under visible light. Energy \& Environmental Science 2011, 4, 914-920. 
35. Zhang, J. F.; Liu, J. Y.; Xi, L. F.; Yu, Y. F.; Chen, N.; Sun, S. H.; Wang, W. C.; Lange, K. M.; Zhang, B., Single-Atom Au/NiFe Layered Double Hydroxide Electrocatalyst: Probing the Origin of Activity for Oxygen Evolution Reaction. Journal of the American Chemical Society 2018, 140, 38763879.

36. Morales-Guio, C. G.; Mayer, M. T.; Yella, A.; Tilley, S. D.; Gratzel, M.; Hu, X. L., An Optically Transparent Iron Nickel Oxide Catalyst for Solar Water Splitting. Journal of the American Chemical Society 2015, 137, 9927-9936.

37. Hunter, B. M.; Blakemore, J. D.; Deimund, M.; Gray, H. B.; Winkler, J. R.; Muller, A. M., Highly Active Mixed-Metal Nanosheet Water Oxidation Catalysts Made by Pulsed-Laser Ablation in Liquids. Journal of the American Chemical Society 2014, 136, 13118-13121.

38. Ahn, H. S.; Bard, A. J., Surface Interrogation Scanning Electrochemical Microscopy of Ni1$\mathrm{xFexOOH}(0<\mathrm{x}<0.27)$ Oxygen Evolving Catalyst: Kinetics of the "fast" Iron Sites. Journal of the American Chemical Society 2016, 138, 313-318.

39. Gorlin, M.; Chernev, P.; de Araujo, J. F.; Reier, T.; Dresp, S.; Paul, B.; Krahnert, R.; Dau, H.; Strasser, P., Oxygen Evolution Reaction Dynamics, Faradaic Charge Efficiency, and the Active Metal Redox States of Ni-Fe Oxide Water Splitting Electrocatalysts. Journal of the American Chemical Society 2016, $138,5603-5614$.

40. Dong, Y.; Zhang, P. X.; Kou, Y. L.; Yang, Z. Y.; Li, Y. P.; Sun, X. M., A First-Principles Study of Oxygen Formation Over NiFe-Layered Double Hydroxides Surface. Catalysis Letters 2015, 145, 1541-1548.

41. Cai, Z. Y.; Bu, X. M.; Wang, P.; Ho, J. C.; Yang, J. H.; Wang, X. Y., Recent advances in layered double hydroxide electrocatalysts for the oxygen evolution reaction. Journal of Materials Chemistry A 2019, 7, 5069-5089. 
42. Bernard, P.; Gabrielli, C.; Keddam, M.; Takenouti, H.; Leonardi, J.; Blanchard, P., Ac quartz crystal microbalance applied to the studies of the nickel-hydroxide behavior in alkaline-solutions. Electrochimica Acta 1991, 36, 743-746.

43. Benmouhoub, C.; Agrisuelas, J.; Benbrahim, N.; Pillier, F.; Gabrielli, C.; Kadri, A.; Pailleret, A.; Perrot, H.; Sel, O., Influence of the Incorporation of $\mathrm{CeO}_{2}$ Nanoparticles on the Ion Exchange Behavior of Dodecylsulfate Doped Polypyrrole Films: Ac-Electrogravimetry Investigations. Electrochimica Acta 2014, 145, 270-280.

44. Gao, W. L.; Sel, O.; Perrot, H., Electrochemical and viscoelastic evolution of dodecyl sulfatedoped polypyrrole films during electrochemical cycling. Electrochimica Acta 2017, 233, 262-273.

45. Trotochaud, L.; Young, S. L.; Ranney, J. K.; Boettcher, S. W., Nickel-Iron Oxyhydroxide Oxygen-Evolution Electrocatalysts: The Role of Intentional and Incidental Iron Incorporation. Journal of the American Chemical Society 2014, 136, 6744-6753.

46. Corrigan, D. A., The catalysis of the oxygen evolution recation by iron impurities in thin-film nickel-oxide electrodes. Journal of the Electrochemical Society 1987, 134, 377-384.

47. Stevens, M. B.; Trang, C. D. M.; Enman, L. J.; Deng, J.; Boettcher, S. W., Reactive Fe-Sites in $\mathrm{Ni} / \mathrm{Fe}$ (Oxy)hydroxide Are Responsible for Exceptional Oxygen Electrocatalysis Activity. Journal of the American Chemical Society 2017, 139, 11361-11364.

48. Gao, X. Y.; Pan, X. Y.; Long, X.; Yi, Z. G., Room-Temperature Synthesis FeNiCo Layered Double Hydroxide as an Excellent Electrochemical Water Oxidation Catalyst. Journal of the Electrochemical Society 2017, 164, II755-II759.

49. Seron, A.; Delorme, F., Synthesis of layered double hydroxides (LDHs) with varying pH: A valuable contribution to the study of $\mathrm{Mg} / \mathrm{Al} \mathrm{LDH}$ formation mechanism. Journal of Physics and Chemistry of Solids 2008, 69, 1088-1090. 
50. Sauerbrey, G., Verwendung von schwingquarzen zur wagung dunner schichten und zur mikrowagung. Zeitschrift Fur Physik 1959, 155, 206-222.

51. Bizet, K.; Gabrielli, C.; Perrot, H., Immunodetection by quartz crystal microbalance - A new approach for direct detection of rabbit IgG and peroxidase. Applied Biochemistry and Biotechnology 2000, $89,139-149$.

52. Gabrielli, C.; Garcia-Jareno, J. J.; Keddam, M.; Perrot, H.; Vicente, F., Ac-electrogravimetry study of electroactive thin films. I. Application to Prussian Blue. Journal of Physical Chemistry B 2002, $106,3182-3191$.

53. Gabrielli, C.; Garcia-Jareno, J. J.; Keddam, M.; Perrot, H.; Vicente, F., Ac-electrogravimetry study of electroactive thin films. II. Application to polypyrrole. Journal of Physical Chemistry B 2002, $106,3192-3201$.

54. Hunter, B.; Winkler, J.; Gray, H.; Mueller, A., Effect of interlayer anions on NiFe-LDH nanosheet water oxidation activity. Abstracts of Papers of the American Chemical Society 2016, 251, 1.

55. Bookin, A. S.; Cherkashin, V. I.; Drits, V. A., Reinterpretation of the X-ray-diffraction patterns of stichtite and reevesite. Clays and Clay Minerals 1993, 41, 631-634.

56. Qiu, J. B.; Villemure, G., Anionic clay-modified electrodes - Electrochemical activity of nickel(II) sites in layered double hydroxide films. Journal of Electroanalytical Chemistry 1995, 395, 159-166.

57. Qiu, J. B.; Villemure, G., Anionic clay modified electrodes: Electron transfer mediated by electroactive nickel, cobalt or manganese sites in layered double hydroxide films. Journal of Electroanalytical Chemistry 1997, 428, 165-172.

58. Corrigan, D. A.; Bendert, R. M., Effect of coprecipitated metal-ions on the electrochemistry of nickel-hydroxide thin-films - cyclic voltammetry in 1M KOH. Journal of the Electrochemical Society 1989, $136,723-728$. 
59. Song, F.; Hu, X. L., Exfoliation of layered double hydroxides for enhanced oxygen evolution catalysis. Nature Communications 2014, 5, 4477.

60. Friebel, D.; Louie, M. W.; Bajdich, M.; Sanwald, K. E.; Cai, Y.; Wise, A. M.; Cheng, M. J.; Sokaras, D.; Weng, T. C.; Alonso-Mori, R.; Davis, R. C.; Bargar, J. R.; Norskov, J. K.; Nilsson, A.; Bell, A. T., Identification of Highly Active Fe Sites in (Ni,Fe)OOH for Electrocatalytic Water Splitting. Journal of the American Chemical Society 2015, 137, 1305-1313.

61. Scavetta, E.; Berrettoni, M.; Giorgetti, M.; Tonelli, D., Electrochemical characterisation of Ni/AlX hydrotalcites and their electrocatalytic behaviour. Electrochimica Acta 2002, 47, 2451-2461.

62. Arias, C. R.; Debiemme-Chouvy, C.; Gabrielli, C.; Laberty-Robert, C.; Pailleret, A.; Perrot, H.; Sel, O., New Insights into Pseudocapacitive Charge-Storage Mechanisms in Li-Birnessite Type $\mathrm{MnO}_{2}$ Monitored by Fast Quartz Crystal Microbalance Methods. Journal of Physical Chemistry C 2014, 118, 26551-26559.

63. Escobar-Teran, F.; Arnau, A.; Garcia, J. V.; Jimenez, Y.; Perrot, H.; Sel, O., Gravimetric and dynamic deconvolution of global EQCM response of carbon nanotube based electrodes by Acelectrogravimetry. Electrochemistry Communications 2016, 70, 73-77.

64. Goubaa, H.; Escobar-Teran, F.; Ressam, I.; Gao, W.; El Kadib, A.; Lucas, I. T.; Raihane, M.; Lahcini, M.; Perrot, H.; Sel, O., Dynamic Resolution of Ion Transfer in Electrochemically Reduced Graphene Oxides Revealed by Electrogravimetric Impedance. Journal of Physical Chemistry C 2017, 121, 9370-9380.

65. Jaffee, R. I.; Smith, E. M.; Gonser, B. W., The constitution of the gold germanium system. Transactions of the American Institute of Mining and Metallurgical Engineers 1945, 161, 366-372. 
66. Kim, M. S.; Kim, K. B., A study on the phase transformation of electrochemically precipitated nickel hydroxides using an electrochemical quartz crystal microbalance. Journal of the Electrochemical Society 1998, 145, 507-511.

67. Wehrens-Dijksma, M.; Notten, P. H. L., Electrochemical Quartz Microbalance characterization of $\mathrm{Ni}(\mathrm{OH})_{2}$-based thin film electrodes. Electrochimica Acta 2006, 51, 3609-3621.

68. Hunter, B. M.; Winkler, J. R.; Gray, H. B., Iron Is the Active Site in Nickel/Iron Water Oxidation Electrocatalysts. Molecules 2018, 23, 903.

69. Sanson, A.; Kantor, I.; Cerantola, V.; Irifune, T.; Carnera, A.; Pascarelli, S., Local structure and spin transition in $\mathrm{Fe}_{2} \mathrm{O}_{3}$ hematite at high pressure. Physical Review B 2016, 94, 014112.

70. Likos, W. J.; Lu, N., Pore-scale analysis of bulk volume change from crystalline interlayer swelling in $\mathrm{Na}^{+}$- and $\mathrm{Ca}^{2+}$-smectite. Clays and Clay Minerals 2006, 54, 515-528.

71. Kittrick, J. A., Interlayer forces in montmorillonite and vermiculite. Soil Science Society of America Proceedings 1969, 33, 217-222.

72. Norrish, K., The swelling of montmorillonite. Discussions of the Faraday Society 1954, 18, 120134.

73. Laird, D. A., Model for crystalline swelling of 2:1 phyllosilicates. Clays and Clay Minerals 1996, $44,553-559$.

74. Rattan, L.; K., S. M., Principle of soil Physics. Marcel Dekker: New York, 2004.

75. Stucki, J. W.; Low, P. F.; Roth, C. B.; Golden, D. C., Effects of oxidation-state of octahedral iron on clay swelling. Clays and Clay Minerals 1984, 32 (5), 357-362.

76. Wu, J.; Low, P. F.; Roth, C. B., Effects of octahedral-iron reduction and swelling pressure on interlayer distances in Na-nontronite. Clays and Clay Minerals 1989, 37, 211-218. 
77. Stucki, J. W.; Lee, K.; Zhang, L. Z.; Larson, R. A., Effects of iron oxidation state on the surface and structural properties of smectites. Pure and Applied Chemistry 2002, 74, 2145-2158.

78. Secor, R. B.; Radke, C. J., Spillover of the diffuse double-layer on montmorillonite particles. Journal of Colloid and Interface Science 1985, 103, 237-244. 


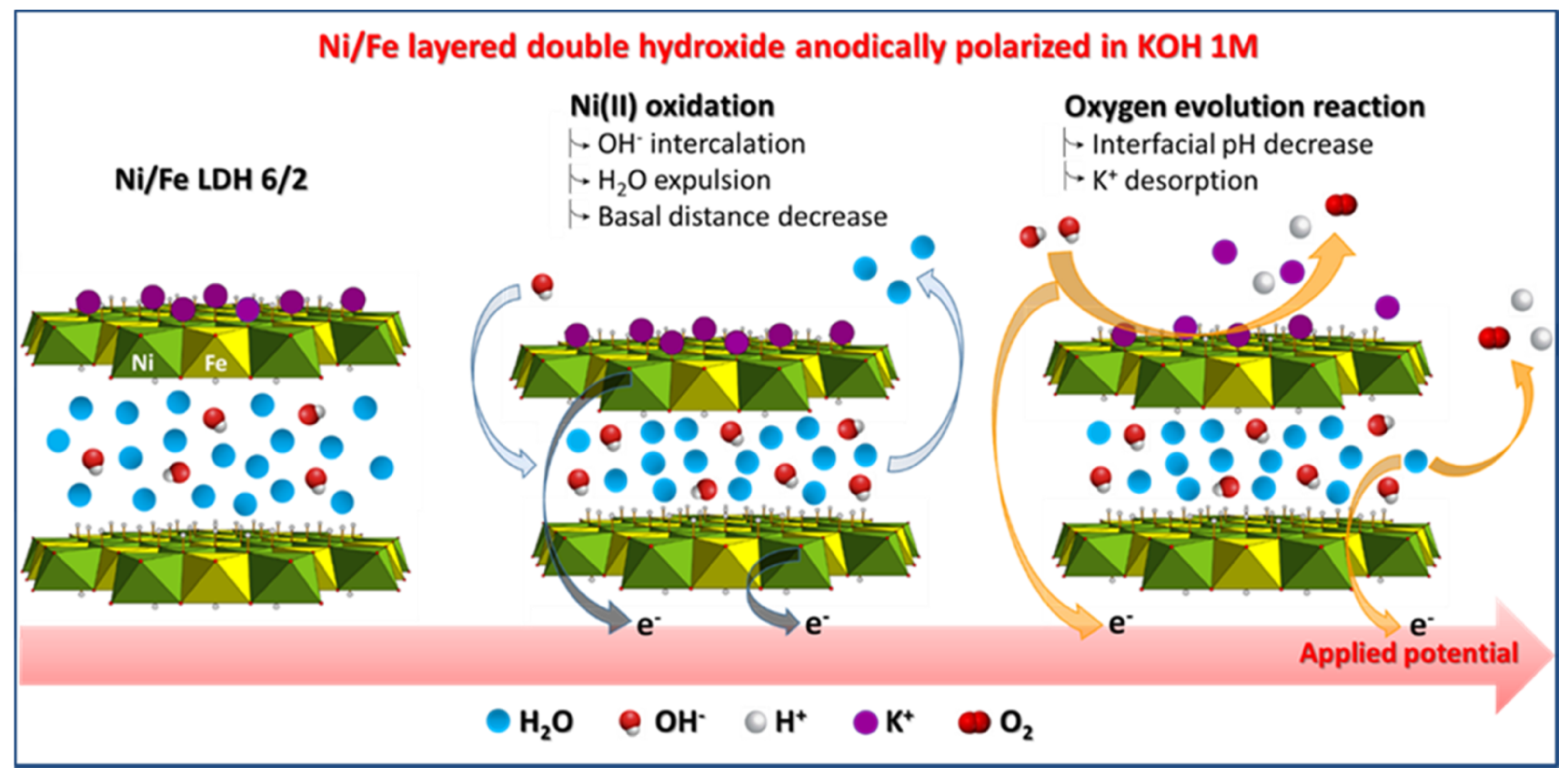

